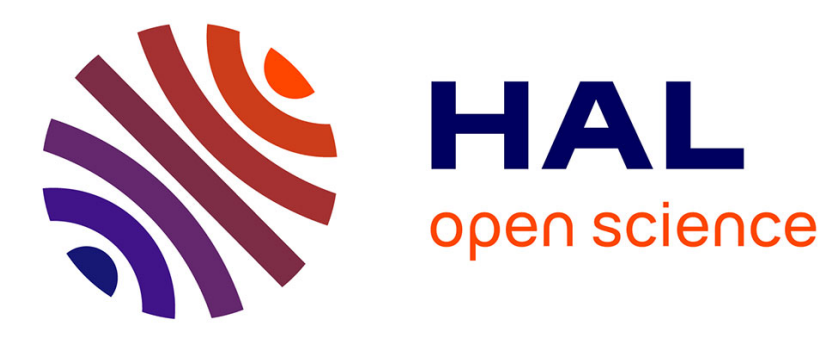

\title{
Rapid Dietary Shift in Podarcis siculus Resulted in Localized Changes in Gut Function
}

\author{
Beck Wehrle, Anthony Herrel, Bao-Quang Nguyen-Phuc, Salvador
}

Maldonado, Robert Dang, Ritika Agnihotri, Zoran Tadić, Donovan German

\section{- To cite this version:}

Beck Wehrle, Anthony Herrel, Bao-Quang Nguyen-Phuc, Salvador Maldonado, Robert Dang, et al.. Rapid Dietary Shift in Podarcis siculus Resulted in Localized Changes in Gut Function. Physiological and Biochemical Zoology, 2020, 93 (5), pp.396-415. 10.1086/709848 . hal-02990312

\section{HAL Id: hal-02990312 \\ https://hal.science/hal-02990312}

Submitted on 9 Nov 2020

HAL is a multi-disciplinary open access archive for the deposit and dissemination of scientific research documents, whether they are published or not. The documents may come from teaching and research institutions in France or abroad, or from public or private research centers.
L'archive ouverte pluridisciplinaire $\mathbf{H A L}$, est destinée au dépôt et à la diffusion de documents scientifiques de niveau recherche, publiés ou non, émanant des établissements d'enseignement et de recherche français ou étrangers, des laboratoires publics ou privés. 


\section{Physiological and Biochemical Zoology \\ Rapid dietary shift in Podarcis siculus resulted in localized changes in gut function --Manuscript Draft--}

\begin{tabular}{|c|c|}
\hline Manuscript Number: & 19104R2 \\
\hline Full Title: & Rapid dietary shift in Podarcis siculus resulted in localized changes in gut function \\
\hline Short Title: & Podarcis siculus gut function \\
\hline Article Type: & Research Paper \\
\hline Corresponding Author: & $\begin{array}{l}\text { Beck Ari Wehrle, PhD } \\
\text { University of California Irvine } \\
\text { Irvine, CA UNITED STATES }\end{array}$ \\
\hline \multicolumn{2}{|l|}{$\begin{array}{l}\text { Corresponding Author Secondary } \\
\text { Information: }\end{array}$} \\
\hline Corresponding Author's Institution: & University of California Irvine \\
\hline \multicolumn{2}{|l|}{$\begin{array}{l}\text { Corresponding Author's Secondary } \\
\text { Institution: }\end{array}$} \\
\hline First Author: & Beck Ari Wehrle, PhD \\
\hline \multicolumn{2}{|l|}{ First Author Secondary Information: } \\
\hline \multirow[t]{8}{*}{ Order of Authors: } & Beck Ari Wehrle, PhD \\
\hline & Anthony Herrel, PhD \\
\hline & Bao-Quang Nguyen-Phuc, DC \\
\hline & Salvador Maldonado, BS \\
\hline & Robert K. Dang, BS \\
\hline & Ritika Agnihotri, MS \\
\hline & Zoran Tadić, PhD \\
\hline & Donovan P. German, PhD \\
\hline \multicolumn{2}{|c|}{ Order of Authors Secondary Information: } \\
\hline Abstract: & $\begin{array}{l}\text { Natural dietary shifts offer the opportunity to address the nutritional physiological } \\
\text { characters required to thrive on a particular diet. Here, we studied the nutritional } \\
\text { physiology of Podarcis siculus , populations of which on Pod Mrčaru, Croatia, have } \\
\text { become omnivorous and morphologically distinct (including the development of valves } \\
\text { in the hindgut) from their insectivorous source population on Pod Kopište. We } \\
\text { compared gut structure and function between the two island populations of this lizard } \\
\text { species and contrasted them with an insectivorous mainland outgroup population in } \\
\text { Zagreb. Based on the Adaptive Modulation Hypothesis, we predicted changes in gut } \\
\text { size and structure, digestive enzyme activities, microbial fermentation products } \\
\text { (SCFAs), and plant material digestibility concomitant with this dietary change. The Pod } \\
\text { Mrčaru population had heavier guts than the mainland population, but no other } \\
\text { differences in gut structure. Most of the enzymatic differences we detected were } \\
\text { between the island populations and the outgroup population. The Pod Mrčaru lizards } \\
\text { had higher amylase and trehalase activities in their hindguts compared to the Pod } \\
\text { Kopište population, the Pod Kopište lizards had greater SCFA concentrations in their } \\
\text { hindguts than the plant-eating Pod Mrčaru population. Interestingly, the differences } \\
\text { between the Pod Mrčaru and Pod Kopište populations are primarily localized to the } \\
\text { hindgut and are likely influenced by microbial communities and a higher food intake by } \\
\text { the Pod Mrčaru lizards. Although subtle, the changes in hindgut digestive physiology } \\
\text { impact digestibility of plant material- Pod Mrčaru lizards had higher digestibility of } \\
\text { herbivorous and omnivorous diets in the laboratory than did their source population. }\end{array}$ \\
\hline
\end{tabular}




\section{Rapid dietary shift in Podarcis siculus resulted in localized changes in gut}

2 function

3 Beck A. Wehrle ${ }^{1}$, Anthony Herrel ${ }^{2}$, Bao-Quang Nguyen-Phuc ${ }^{1}$, Salvador Maldonado Jr. ${ }^{1}$, Robert

$4 \quad$ K. Dang ${ }^{1}$, Ritika Agnihotri ${ }^{1}$, Zoran Tadic ${ }^{3}$, and Donovan P. German ${ }^{1}$

$6{ }^{1}$ Department of Ecology and Evolutionary Biology, University of California, 321 Steinhaus Hall,

7 Irvine, CA 92697-2525, USA; ${ }^{2}$ Départment Adaptation du Vivant, Centre National de la

8 Recherche, Scientifique/ Muséum National d'Historie Naturelle, Paris, France, ${ }^{3}$ Department of

9 Biology, University of Zagreb, Rooseveltov trg 6, Zagreb, Croatia

\section{Correspondence Author}

12 Beck A. Wehrle

13 Department of Ecology and Evolutionary Biology

$14 \quad 321$ Steinhaus Hall

15 University of California

16 Irvine, CA 92697-2525, USA

17 Beck.wehrle@gmail.com 


\section{Abstract}

20 Natural dietary shifts offer the opportunity to address the nutritional physiological characters

21 required to thrive on a particular diet. Here, we studied the nutritional physiology of Podarcis

22 siculus, populations of which on Pod Mrčaru, Croatia, have become omnivorous and

23 morphologically distinct (including the development of valves in the hindgut) from their

24 insectivorous source population on Pod Kopište. We compared gut structure and function

25 between the two island populations of this lizard species and contrasted them with an

26 insectivorous mainland outgroup population in Zagreb. Based on the Adaptive Modulation

27 Hypothesis, we predicted changes in gut size and structure, digestive enzyme activities,

28 microbial fermentation products (SCFAs), and plant material digestibility concomitant with this

29 dietary change. The Pod Mrčaru population had heavier guts than the mainland population, but

30 no other differences in gut structure. Most of the enzymatic differences we detected were

31 between the island populations and the outgroup population. The Pod Mrčaru lizards had higher

32 amylase and trehalase activities in their hindguts compared to the Pod Kopište population, the

33 Pod Kopište lizards had greater SCFA concentrations in their hindguts than the omnivorous Pod

34 Mrčaru population. Interestingly, the differences between the Pod Mrčaru and Pod Kopište

35 populations are primarily localized to the hindgut and are likely influenced by microbial

36 communities and a higher food intake by the Pod Mrčaru lizards. Although subtle, the changes in

37 hindgut digestive physiology impact digestibility of plant material in adult lizards — Pod Mrčaru

38 lizards had higher digestibility of herbivorous and omnivorous diets fed over several weeks in

39 the laboratory than did their source population.

40

$41 \quad$ Keywords 
42 digestion, enzyme, gut, intestine, lizard, omnivory, physiology

\section{$44 \quad$ Introduction}

Based on Optimal Foraging Theory (Pyke et al. 1977) and Chemical Reactor Theory (Penry and

47 Jumars 1987), the Adaptive Modulation Hypothesis (AMH; Karasov and Diamond 1983;

48 Karasov 1992; Karasov and Martínez del Rio 2007) uses economic principles, arguing that the

49 gut is expensive to maintain, and thus, there should be a match between gut function (digestive

50 enzyme activities, nutrient transport rates) and the food ingested by an animal. Thus, to

51 maximize net nutrient gain, a diet shift should lead to changes in gut physiology to match the

52 new diet, on short or long timescales. For example, increased digestive substrate concentration

53 (e.g., starch) requires increases in matched enzyme activities (e.g., amylase activity) to achieve

54 high digestibility of the nutrient (Karasov and Martínez del Río 2007). Indeed, correlations

55 between carbohydrase activities in the gut and carbohydrate intake in the natural diet has been

56 observed in fishes, birds, and mammals, even when analyzed in a phylogenetic context

57 (Schondube et al. 2001; Horn et al. 2006; Perry et al. 2007; German et al. 2010; Kohl et al. 2011;

58 German et al. 2015). Some herbivorous fishes that consume starch-rich diets cannot down

59 regulate their digestive enzyme activities towards carbohydrates (German et al. 2004) or

60 intestinal glucose transport rates (Buddington et al. 1987) when fed low-starch foods in the

61 laboratory, suggesting that expression of the requisite enzymes and transporters can be fixed in

62 some animals. The same cannot be said for proteolytic enzymes, where evolutionary correlations

63 of dietary protein and gut proteolytic activity are weak or non-existent (e.g., Schondube et al.

64 2001; German et al. 2010; Kohl et al. 2011); although there are examples of short term flexibility 
65 in proteolytic enzyme activities in many species (reviewed in Caviedes-Vidal et al. 2000 and 66 Leigh at al. 2018a).

67 In terms of gut size, increased food intake (e.g., due to high-fiber content of the diet)

68 speeds up digesta transit rate (Dadd 1960; Pritchard and Robbins 1990; Diamond 1991; Castle

69 and Wunder 1995), and more rapid digesta transit rates requires an increase in gut size and/or

70 some way to slow down digesta transit to maintain digestibility (Sibly 1981; Karasov and Hume

71 1997; Karasov and Martínez del Rio 2007; Karasov and Douglas 2013). Hence, herbivores

72 generally have larger guts than carnivores (Wagner et al. 2009; Stevens and Hume 2004; Dearing

73 1993) to accommodate more voluminous meals (Pough 1973; Wilson and Lee 1987). Hindgut

74 valves (like the ones observed in a Lacertid lizard: see below) can both increase overall gut

75 surface area and can slow the passage of digesta (Iverson 1982; Stevens and Hume 2004; Bignell

76 1984; Bell et al. 2005; Godon et al. 2016). Digesta high in fiber (i.e. plant material) is

77 particularly viscous, characterized by low Reynolds Numbers (Lentle and Jansen 2008). Because

78 of these flow characteristics, digesta high in fiber leads to decreased mixing in a smooth-bore

79 tube (Love et al. 2013). By acting as "baffles," hindgut valves can increase mixing of viscous

80 digesta in what would otherwise be a plug-flow environment with unidirectional flow (Lentle

81 and Jansen 2008), thus helping to maintain nutrient digestibility by increasing the residence time

82 of digesta in that gut region (Stevens and Hume 2004; Karasov and Martínez del Rio 2007). We,

83 therefore, predict that animals eating plants would have features of gut structure (e.g., larger gut,

84 hindgut valves) and function (e.g., elevated carbohydrase activities, in congruence with AMH)

85 that facilitate digestion of plant material (Table 1; Karasov and Martínez del Rio 2007).

86 Beyond endogenous digestive processes like digestive enzyme synthesis and secretion,

87 many herbivores and omnivores rely on microbial symbioses, usually in the hindgut, to digest 
more fibrous portions of plants (e.g., cellulose) and can derive some portion of their energy

89 intake from microbial fermentation (McBee and McBee 1982; Bjorndal 1997; Stevens and Hume

90 1998). These microbial fermentations produce short chain fatty acids (SCFA) that can be

91 assimilated across the gut wall by the host (Bergman 1990; Foley et al. 1992). Thus, animals

92 consuming more plant material may have increased reliance on microbial fermentation (in this

93 study, indirectly measured via the products of fermentation, SCFA) in their hindguts to

94 assimilate their plant meals (Stevens and Hume 1998).

95 One of the most interesting examples of a rapid dietary shift in a vertebrate animal is in

96 the Italian Wall Lizard, Podarcis siculus. In 1971, five male-female pairs of P. siculus were

97 moved from the island of Pod Kopište $\left(0.09 \mathrm{~km}^{2}\right)$, Croatia, to the nearby island of Pod Mrčaru

$98\left(0.03 \mathrm{~km}^{2}\right)$ as part of a biological invasion study (Fig. 1; Nevo et al. 1972). Returning to the

99 Croatian islets in 2004-2006 (<30 P. siculus generations later), Herrel et al. (2008) found the new

100 population on Pod Mrčaru had morphologically and behaviorally diverged from their source

101 population on Pod Kopište. Although the Pod Kopište lizards were insectivorous, consuming 4-

$1027 \%$ plant material (by mass), plants made up 34-61\% of the Pod Mrčaru population's intake.

103 Plant material was more available on Pod Mrčaru, but arthropod abundance and diversity was

104 similar between islands (A. Herrel, unpublished data). The Pod Mrčaru lizards were larger, had

105 different head shapes, and larger bite forces. Additionally, both adult and neonate lizards from

106 Pod Mrčaru had developed valves in their hindguts, a feature not found in the Pod Kopište

107 population. Hindgut valves in lizards are generally associated with highly derived herbivory

108 (Iverson 1982; Bjorndal 1997; Stevens and Hume 2004). Morphological and dietary changes

109 have been documented between the Pod Mrčaru lizards and their source population on Pod 
110 Kopište (Herrel et al. 2008); however it is unknown if the appearance of hindgut valves is

111 concomitant with other shifts in gut morphology or function.

112 In this study, we examined gut structure (gut length, histological surface area) and

113 function (digestive enzyme activities, organic matter digestibility) in the context of diet

114 (proportion plant material, mass of stomach contents) in P. siculus from the two Croatian islets,

115 as well as from Zagreb on the mainland (Fig. 1). Omnivory and herbivory in lizards is rare, with

116 herbivory encompassing $<1-4 \%$ of extant lizards (Espinoza et al. 2004; Cooper and Vitt 2001;

117 King 1996). Yet, strict herbivory has originated independently >30 times (Espinoza et al. 2004)

118 adding to the compelling reasons to investigate the mechanisms behind such shifts to plant-rich

119 diets. We tested the assumption that there have been unique shifts in gut structure and function in

120 the Pod Mrčaru lizards allowing them to digest plant material better than lizards from Pod

121 Kopište or the mainland (Zagreb). If pancreatic or brush border enzymes aimed at digesting

122 components of plant material are higher in the Pod Mrčaru lizards than their insectivorous

123 counterparts on Pod Kopište (Fig. 2; Table 1), this would support the AMH, and we can

124 conclude that the lizards have increased relevant enzyme activities (e.g., via increased expression

125 of digestive enzyme genes; German et al. 2016). If digestive enzyme activities aimed at digesting

126 plant material, particularly the fibrous portions, are elevated in the lizards' hindguts, these

127 enzymes would likely be microbially derived (Potts and Hewitt 1973; Nakashima et al. 2002; Mo

128 et al. 2004; Skea et al. 2005; German et al. 2015; Jhaveri et al. 2015; Leigh et al. 2018b; Fig. 2;

129 Table 1). Elevated SCFA concentrations would also support a role of symbionts (Table 1). All of

130 these possibilities are not mutually exclusive, as lizard tissue changes and microbial community

131 shifts may both contribute to the Pod Mrčaru omnivores' ability to subsist on a diet rich in plants. 


\section{Materials and Methods}

135 Diet analysis

136 From August 29-September 2, 2013, we flushed the stomachs of Podarcis siculus from the islets

137 of Pod Mrčaru ( $n=36)$ and Pod Kopište ( $n=31$, reduced to $n=30$ due to an empty stomach),

138 Croatia, following Herrel et al. (2006, 2008). Stomach contents were stored in 70\% ethanol.

139 Contents from Zagreb lizards ( $n=7$, reduced to $n=4$ due to three empty stomachs) were obtained

140 from frozen-stored stomachs from previously dissected animals. We divided stomach contents

141 into plant matter, arthropods, and “other," weighing each category to the nearest 0.1-mg We

142 treated stomach contents as a proxy for ingested diet and determined the total mass and the

143 relative proportion of plant and arthropod prey.

145 Animal collection, dissection, measurements of gut size, and tissue preservation

146 From August 26-29, 2013, we collected 13 male $P$. siculus from each islet, Pod Kopište and Pod

147 Mrčaru. We captured all lizards in the morning after they became active. Lizards were kept

148 individually in cloth bags and were euthanized and dissected upon returning to the laboratory

149 (within four hours). As an outgroup (Podnar et al. 2005), we collected 13 P. siculus from an

150 urban population in Zagreb from September 15-October 4, 2013.

151 Lizards were weighed to the nearest $0.1-\mathrm{g}$ and euthanized via intramuscular injections of

152 sodium pentobarbital ( 0.1mg/g-tissue). We measured snout-vent length (SVL) and dissected the

153 lizards on sterilized, chilled dissecting trays $\left(\sim 4^{\circ} \mathrm{C}\right)$. We removed and measured the length of the

154 gut from beginning of the esophagus to the end of the hindgut (hereafter: gut length). 
155 We divided the gut into stomach (including esophagus), proximal intestine (PI), mid intestine

156 (MI), and hindgut (H). The hindgut was easily identifiable (see Fig. 2) and the proximal and mid

157 intestine portions were separated by dividing the remaining intestine in half. In seven individuals

158 from each population, we removed the gut contents from the proximal, mid, and hindgut sections

159 (e.g., Proximal Intestine Gut Contents, PIGC; Hindgut Contents, HC) and flushed out the

160 intestinal tissue with chilled $25 \mathrm{mM}$ tris- $\mathrm{HCl}, \mathrm{pH}$ 7.5. We used $\mathrm{pH}$ indicator paper (Macherey-

161 Nagel, Düren, Germany: pH 1-14, 5.5-9.0, and 8.0-10.0) on dissected Zagreb lizards to measure

$162 \mathrm{pH}$ of the contents of each gut region as follows: stomach $\mathrm{pH} 3.4 \pm 2.0$, proximal intestine $\mathrm{pH}$

$1638.17 \pm 0.6$, mid intestine $\mathrm{pH} 8.96 \pm 0.7$, and hindgut $\mathrm{pH} 8.75 \pm 0.5$.

164

165 Gut tissues and contents from each gut region and pancreases were frozen separately in

$1661.5 \mathrm{~mL}$ vials in liquid nitrogen for storage and transport. Vials were transported on dry ice to the

167 University of California, Irvine, where they were stored at $-80^{\circ} \mathrm{C}$ until used. We weighed frozen

168 gut sections and gut contents (excluding stomachs) to the nearest $0.001 \mathrm{~g}$. For three lizards from

169 each population, we preserved the PI, MI, and H in McDowell Trump's fixative (4\%

170 formaldehyde, $1 \%$ glutaraldehyde, McDowell and Trump 1976) for subsequent histological

171 analyses. The remaining three lizards from each population were used for microbiome analyses

172 in a different study (Lemieux-Labonté et al., Unpubl data).

173

174 Estimation of intestinal surface area using histology

175 Gut sections preserved in Trump's Solution were further sectioned into 3-10 mm sections with a

176 razor blade and rinsed in phosphate buffer $\mathrm{pH} 7.5$ (PBS) for 3 x 20 min., and overnight in PBS at

$177 \quad 4^{\circ} \mathrm{C}$ under constant shaking. The PBS rinsed tissues were flushed with running deionized water 
178 for 2 x 20 min., and then were subjected to serial ethanol dilutions of $30 \%, 50 \%$, and $75 \%$. We

179 selected the proximal portions of the PI, MI, and H from Pod Mrčaru and Pod Kopište lizards, 180 and portions starting at the halfway point of the hindgut $(\mathrm{H}+)$ from all three populations. Tissue

181 portions were placed in tissue cassettes wrapped in ethanol-soaked cheesecloth, sealed in plastic

182 bags, and were sent to Mass Histology Services (Worcester, MA, USA) for embedding in

183 paraffin wax. We stained 7- $\mu$ m sectioned samples with hematoxylin and eosin and imaged them

184 with a Zeiss Axioplan 2 epifluorescence microscope and Zeiss and Cannon cameras. Tiled

185 images were assembled using the Photomerge function of Adobe Photoshop CS3. We analyzed

186 1-25 sections of each sample by measuring the perimeters of mucosa and serosa. We then

187 calculated the epithelial surface magnification (ESM) as the ratio of mucosal to serosal

188 perimeters (Hall and Bellwood 1995; German 2009) to observe how much the mucosal folds

189 increase the inner surface area of the intestine relative to a smooth bore tube.

191 Homogenate preparation

192 We homogenized frozen tissues following German and Bittong (2009). We diluted the tissues in 193 the following chilled buffers: pancreases (P) diluted 50-300 volumes and gut contents (PIGC,

194 MIGC, $\mathrm{HC}$ pellet) diluted 5-300 volumes in $25 \mathrm{mM}$ tris- $\mathrm{HCl}$ buffer, $\mathrm{pH} 8.6$ and, intestinal wall 195 tissues (PI, MI, or $\mathrm{H}$ ) diluted 10-50 volumes in $350 \mathrm{mM}$ mannitol in $1 \mathrm{mM}$ Tris- $\mathrm{HCl}, \mathrm{pH}$ 8.6. We 196 chose buffers at $\mathrm{pH} 8.6$ because it was the average $\mathrm{pH}$ we measured in the intestinal contents of 197 the P. siculus from Zagreb. For all tissues, we used a Polytron homogenizer (Binkmann 198 Instruments, Westbury, NY) with a $12 \mathrm{~mm}$ generator set to $1100-3000 \mathrm{rpm}$ for $3 \times 30 \mathrm{~s}$, with $30 \mathrm{~s}$ 199 between pulses to homogenize tissues. Tissue homogenates were centrifuged at $9400 \mathrm{x} g$ for 2 200 min. To ensure the rupture of the microbial cells and the release of all enzymes within gut 
201 content samples, these samples were sonicated (CL-18 Sonicator, Fisher Scientific, Waltham,

202 Massachusetts, USA) at $5 \mathrm{~W}$ output for 3 x $30 \mathrm{~s}$, with $30 \mathrm{~s}$ intervals between pulses, followed by

203 homogenization, as described for the gut tissues. The gut content samples were centrifuged at

$20412000 \times \mathrm{x}$ for $10 \mathrm{~min}$. All supernatants were stored in $100-200 \mu \mathrm{l}$ aliquots at $-80^{\circ} \mathrm{C}$ until just

205 before use in digestive enzyme assays. For the HC, we thawed the sample enough to transfer the

206 contents to a spin column (Corning Costar Spin-X Centrifuge cellulose acetate tube filters, 0.22

$207 \mu \mathrm{m}$ pores) and centrifuged at $14000 \times \mathrm{g}$ at $4^{\circ} \mathrm{C}$ to gather $\mathrm{H}$ fluid. The filtered fluid was frozen at -

$20880^{\circ} \mathrm{C}$ for use in SCFA measurements. The remaining HC pellet was then prepared for enzyme

209 assays in the same manner as the other gut contents (German and Bittong 2009).

211 Biochemical Assays of Digestive Enzyme Activity

212 We conducted digestive enzyme assays following protocols outlined in German and Bittong

213 (2009) and German et al. (2015). We ran all assays at $25^{\circ} \mathrm{C}$, the mean temperature from May-

214 September (confirmed by iButtons, Maxim Integrated, San Jose, CA, USA; Supplemental Fig.

215 S1) on the islands and within the preferred temperature range of $P$. siculus populations outside of

216 their native geographic range (Liwanag et al. 2018). We measured enzyme activities in duplicate

217 or triplicate and read absorption or fluorescence in flat-bottomed 96-well microplates using a

218 BioTek Synergy H1 Hybrid spectrophotometer/ fluorometer equipped with a monochromator

219 (BioTek, Winooski, VT, USA). Our primary buffer was 25mM Tris-HCl, pH 8.6 (referred to

220 henceforth as "buffer," any deviations are noted), measured at room temperature $\left(22^{\circ} \mathrm{C}\right)$.

221 Reagents were purchased from Sigma-Aldrich (St. Louis, MO, USA). We optimized each assay

222 for duration and homogenate volume. Each enzyme activity was measured in each gut region (PI,

223 MI, H, PIGC, MIGC, HC) for each lizard. Pancreatic tissue was only used for measuring 
224 pancreatic enzyme activity (i.e.: $\alpha$-amylase, trypsin, and lipase). We simultaneously conducted

225 control experiments using homogenate or substrate blanks in buffer to check for endogenous

226 substrate and/or product in the substrate solutions. For all kinetic assays, we determined the slope

227 of the longest linear section of absorbance vs. time and used the standard curve of the product to

228 calculate enzymatic activity $U$ per gram wet mass of tissue.

229

230 Carbohydrate degrading enzymes-Following German and Bittong (2009) and German et al.

231 (2015), we measured $\alpha$-amylase activity using $1 \%$ potato starch dissolved in buffer containing 1

$232 \mathrm{mM} \mathrm{CaCl}_{2}$. Maltase and trehalase activities were measured using $112 \mathrm{mM}$ maltose or trehalose,

233 respectively, in buffer. We incubated each of these assays as end-point reactions. Post

234 termination, we determined glucose concentration by measuring absorbance at $650 \mathrm{~nm}(\alpha-$

235 amylase) and $550 \mathrm{~nm}$ (maltase and trehalase). The $\alpha$-amylase, maltase, and trehalase activities

236 were determined from glucose standard curves and expressed in $\mathrm{U}(\mu \mathrm{mol}$ glucose liberated per

237 minute) per gram of tissue.

238 We measured $\beta$-glucosidase, $\beta$-galactosidase, and N-acetyl- $\beta$-D-glucosaminidase (NAG)

239 at following German et al. (2011) and German et al. (2015) using $200 \mu \mathrm{M}$ solutions of 4-

240 methylumbelliferyl- $\beta$-D-glucoside, methylumbelliferyl- $\beta$-D-galactopyranoside, and 4-

241 methylumbelliferyl-N-acetyl- $\beta$-D-glucosaminide, respectively. Because of the sensitivity of the

242 fluorometric assays, these concentrations far exceed the $K_{m}$ for these enzymes in soils and

243 animals (German et al. 2011). These assays were run as kinetic fluorometric assays read at 365

$244 \mathrm{~nm}$ excitation and $450 \mathrm{~nm}$ emission for $30 \mathrm{~min}$ to detect a 4-methylumbelliferone - MUB

245 product as $\mathrm{U}\left(\mathrm{nmol}\right.$ MUB released $\mathrm{min}^{-1}$ ) per gram of tissue. $\beta$-glucosidase and NAG were

246 chosen since $\beta$-glucosides or $\beta$-glucoaminides would be common in the digestion of plant fiber 
247 or insect exoskeletons, respectively. $\beta$-galactosidase was chosen since is known to be present in

248 lizard genomes (on chromosome 1 in the A. carolinensis genome; ensebl.org) and is produced in

249 lizard guts (Kohl et al. 2016a). Thus, it was used as a comparison with $\beta$-glucosidase to better

250 understand the activity patterns of this latter enzyme and whether it is endogenously or

251 exogenously (i.e., microbially) produced.

252

253 Assays of protein and lipid degrading enzymes - Modified from German and Bittong (2009) and

254 German et al. (2015), we measured trypsin, aminopeptidase, and lipase activities as kinetic

255 assays. To measure trypsin activity, we used 2mM No-benzoyl-L-arginine-p-nitroanilide

256 hydrochloride (BAPNA) substrate dissolved in $100 \mathrm{mM}$ Tris-HCl buffer. For aminopeptidase

257 activity, we used $2.04 \mathrm{mM}$ L-alanine-p-nitroanilide in buffer. These protease assays were read at

$258410 \mathrm{~nm}$ absorbance for $30 \mathrm{~min}$ to detect a p-nitroaniline product as $\mathrm{U}(\mu$ mol $\mathrm{p}$-nitroaniline

259 released $\min ^{-1}$ ) per gram of tissue. For trypsin activities measured in pancreatic tissue

260 homogenates, we pre-incubated the homogenates with $15 \mu$ l enterokinase (4 $\mathrm{U} \mathrm{mL}-1$ in $40 \mathrm{mM}$

261 succinate buffer, $\mathrm{pH} 5.6) / 100 \mu \mathrm{l}$ homogenate for 15 min to change trypsinogen from its

262 zymogen form to active trypsin enzyme, then proceeded with the assay as with the other tissues.

263 We activated lipase in the homogenates via a $15 \mathrm{~min}$ pre-incubation in $5.2 \mathrm{mM}$ sodium

264 cholate at $25^{\circ} \mathrm{C}$, using 2-methoxyethanol as a solvent. We commenced the assay by adding 0.55

$265 \mathrm{mM}$ p-nitrophenyl myristate substrate (in ethanol) and measured absorbance at $405 \mathrm{~nm}$ for 60

266 min to detect the p-nitrophenol product as $\mathrm{U}\left(\mathrm{nmol} \mathrm{p}\right.$-nitrophenol released $\mathrm{min}^{-1}$ ) per gram of

267 tissue.

268 In addition to the regional enzyme activities $\left(\mathrm{U} \mathrm{x} \mathrm{g}^{-1}\right)$, we calculated the total gut enzyme

269 activities as the sum of mass-specific activity for each region multiplied by the tissue mass to 
270 yield total $\mathrm{U}\left(\mu \mathrm{mol}\right.$ product released $\left.\mathrm{min}^{-1}\right)$. We did not include pancreatic samples in total gut 271 enzyme activities as this region does not interact directly with nutrients.

272

273 Fermentation Analyses

274 To determine symbiotic microbial fermentation, we measured the relative concentrations of short 275 chain fatty acids (SCFAs) in the HC fluid (following methodology in Pryor and Bjorndal 2005; 276 German and Bittong 2009; and German et al. 2015) from Pod Kopište (n=3), Pod Mrčaru (n=4), 277 and Zagreb lizards $(n=1)$. (Despite attempting to collect HC fluid from seven Zagreb lizards, we 278 were only able to collect $\geq 1 \mu \mathrm{L}$ from one lizard from this population.) We hand injected $2 \mu \mathrm{L}$ of 279 thawed HC fluid into a 2-m long stainless steel column (3.2 mm ID) packed with 10\% SP-1000 280 and $1 \% \mathrm{H}_{3} \mathrm{PO}_{4}$ on 100/120 Chromosorb W AW (Supelco, Inc., Bellefonte, PA, USA) attached to 281 a Shimadzu GC-mini-2 gas chromatograph with flame ionization detector (Shimadzu Scientific 282 Instruments, Inc., Columbia, MD, USA). We quantified SCFA concentrations via a Hewlett283 Packard HP3392A (Hewlett-Packard Co., Palo Alto, CA, USA) integrator attached to the gas

284 chromatograph. We calibrated the system with an external standard of $100 \mathrm{mg} \mathrm{L}^{-1}$ each of 285 acetate, propionate, isobutyrate, butyrate, isovalerate, and valerate. The SCFA concentrations are 286 expressed as $\mathrm{mM}$ of gut fluid.

289 From September 1-5, 2013, we collected male P. siculus from both Pod Kopište and Pod Mrčaru 290 ( $n=15$ from each island), transported them in individual cloth bags to the University of Zagreb, 291 where they were housed in individual plastic terraria $30 \times 19$ x 14 or $20 \mathrm{~cm}$ with rock 292 substratum, a hide box, and a water dish. For one week, the lizards were allowed to acclimate to 
293 lab conditions, during which they were offered live cockroaches (Blatta sp.) and finely chopped

294 brussels sprouts (Brassica oleracea) daily. Lizards had ad lib access to water throughout the

295 trials. The lab was kept at $25-31^{\circ} \mathrm{C}$ on a $10: 14 \mathrm{~h}$ light/dark schedule. Five lizards from each

296 population were assigned to one of three diets: insectivore, omnivore, or herbivore. On the first

297 day, each lizard was fed $1.56 \pm 0.07 \%$ of its body mass of its assigned diet (or $\sim 0.33 \mathrm{~kJ} / \mathrm{g}$ ), and

298 thereafter $0.77 \pm 0.01 \%$ of its body mass of its assigned diet daily $(\sim 0.16 \mathrm{~kJ} / \mathrm{g})$ for a duration of 11 -

29932 days. Initial SVLs and masses are presented in Supplemental Table S1.

300

301 Diets - Triplicate samples of empty gelatin capsules (size 4) and of each diet were combusted in 302 an IKA c2000 calorimeter. The insectivore $\operatorname{diet}(24.7 \mathrm{~kJ} / \mathrm{g})$ was made of cockroaches, the 303 omnivore diet $(21.4 \mathrm{~kJ} / \mathrm{g})$ was a $50: 50$ by dry mass mixture of the insectivore and herbivore diets, 304 and the herbivore diet $(18.1 \mathrm{~kJ} / \mathrm{g})$ was $30 \%$ by mass dried plant material collected from Pod 305 Mrčaru, including leaves, flowers, and seeds, and 70\% commercial birdseed (primarily millet, 306 flax, hemp seed, and barley). All diets were dried for $>2$ days at $50^{\circ} \mathrm{C}$, ground to $\leq 1 \mathrm{~mm}$ particle

307 size, and supplemented with Herptivite multivitamins and calcium with vitamin D3 (Rep-Cal, 308 Los Gatos, CA) per manufacturer instructions. Diets were weighed out in approximately 309 isocaloric ratios and packed into gelatin capsules. The gelatin capsules add about $14 \mathrm{~kJ} / \mathrm{g}$ of 310 protein to each diet, equally. We recognize that grinding the food to small particle sizes may take 311 away natural particle size differences in the diets of the Pod Kopište and Pod Mrčaru lizards.

312 However, in seeking some control over dietary intake, we chose to grind the food into a common 313 size, and thus, measure digestibility based on more uniform food. This removed potential

314 physical and chemical processing of differentially sized food particles in the lizards, but allowed 315 us to focus on pure chemical digestibility in the laboratory. One previous investigation of whole 
316 meal worm digestibility in these same lizard populations found similar results to ours (Vervust et

317 al. 2010), suggesting that our grinding of the food didn't mask any performance differences

318 among the lizard populations.

320 Feeding - Each lizard was weighed, and gently force fed the gelatin capsule of a known mass of

321 experimental diet using a plunger from a syringe to push the pill into their esophagus. After the

322 pill was in the esophagus or swallowed, we administered water (of equal mass to the

323 experimental diet) into the lizard's mouth via pipette. We adjusted the mass of diet fed at each

324 feeding to maintain lizard body mass $\pm 10 \%$. We prepared three sizes of meals $(+10 \mathrm{mg}$, baseline,

$325-10 \mathrm{mg}$ ) for each diet. If a lizard's body mass increased by $\geq 10 \%$ compared to its initial measured

326 body mass (or if that individual vomited its previous meal), we fed it the smaller meal size at the

327 next feeding. Individuals that lost $\geq 10 \%$ of their initial body mass were given the larger sized

328 meal at their subsequent feeding. We collected all feces and urates daily and measured the SVL

329 of each lizard weekly.

331 Digestibility Analyses - Compiled feces (without urates) from each individual lizard were dried

332 at $50^{\circ} \mathrm{C}$ for $>1$ week and weighed to the nearest $0.001 \mathrm{~g}$.

333 We estimated the organic matter of each diet, of gelatin capsules, and of the dried feces

334 by combusting a portion of the sample (Bjorndal 1989). Samples were dried at $105^{\circ} \mathrm{C}$ in a drying

335 oven for at least 3 hours to remove all moisture, weighed, then combusted in a Lindburg/ Blue M

336 combusting oven (Ashville, NC, USA) at $550^{\circ} \mathrm{C}$ for 3 hours. The combusted remains were

337 considered non-organic ash and we subtracted that mass from the initial mass to determine the 
338 proportion of organic material in the original sample. We calculated apparent organic matter

339 digestibility as

$\frac{(\text { mass food and gelatin capsules ingested-ash })-(\text { feces mass-ash })}{\text { mass food and gelatin capsules ingested-ash }}$.

341 We recognize that this is apparent organic matter digestibility since we didn't account for

342 endogenous organic matter (e.g., sloughed intestinal cells) losses in feces (McConnachie and

343 Alexander 2004; German 2011).

345 Statistical Analyses

346 We preformed all statistical analyses in R (versions 3.3.2-3.6.0). All data were screened for equal

347 variances using a Bartlett's test and normality of residuals using a Shapiro-Wilk's test. If the data

348 were not naturally parametric, we employed transformations. For propionate concentration

349 comparisons, we used Wilcoxin Signed Rank tests. We used Tukey's HSD test with a family

350 error rate of $P=0.10$ for digestibility analyses and $P=0.05$ for all other analyses to identify

351 pairwise differences following any ANOVAs that indicated significant differences. We

352 compared all data among (or between) populations. We compared gut length (including stomach

353 and esophagus) among populations with an ANCOVA, using SVL as a covariate. We summed

354 the masses of the intestinal tissues for each individual lizard to get total intestinal mass and 355 compared both regional and total intestinal masses among populations with ANCOVA, using

356 body mass as a covariate. We divided gut content mass for each region by total gut content mass

357 to determine the proportion of digesta retention in each gut region.

Additionally, we compared gut content mass and $\beta$-glucosidase activity among gut

359 regions within populations. All data were normalized to mass or were proportions, except body

360 mass itself, SVL, and total enzyme activities. We found no effect of covariance between total 
enzyme activity and any measured parameter (lizard mass, SVL, intestinal mass, gut length, and 362 gut content mass), thus report only the results of ANOVAs.

363 To analyze digestibility, we compared data from lizards on the same experimental diets

364 across populations using ANCOVAS. We found instances of covariance between organic matter

365 digestibility and lizard mass, and between digestibility and total intake. No other measured

366 parameter (SVL, duration in days individual was in digestibility trial) covaried with digestibility.

368 Results

369

370 Podarcis siculus from Pod Kopište (SVL: 64.39 $\pm 2.40 \mathrm{~mm}$; average \pm standard deviation) were

371 significantly shorter in body length $\left(F_{2,35}=11.83, P<0.001\right)$ than the populations from Pod

372 Mrčaru (SVL: 68.73 $\pm 2.50 \mathrm{~mm}$ ) and Zagreb (SVL: $68.43 \pm 5.80 \mathrm{~mm}$ ), which were not different

373 from each other. The Zagreb lizards (body mass: $8.9 \pm 1.5 \mathrm{~g}$ ) were significantly more massive

$374\left(F_{2,35}=13.75, P<0.001\right)$ than either island population lizards, and Pod Mrčaru lizards (body mass:

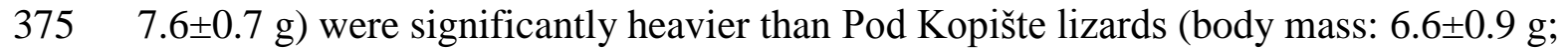

376 Supplemental Table S2).

378 Diet \& Gut Size

379 The newly omnivorous $P$. siculus population on Pod Mrčaru ate larger, more plant rich meals, 380 yet showed none of the increases in gut size expected from such a shift. Lizard stomach content 381 mass varied significantly among the populations $\left(F_{2,68}=16.88, P<0.001\right)$, with Pod Mrčaru lizards 382 having more than double the stomach content masses of the other populations, implying that they 383 consumed more food, at least on an instantaneous scale, than the Pod Kopište and Zagreb 
384 populations. Pod Mrčaru P. siculus (64\% of intake) consumed significantly more plant material $385\left(F_{2,63}=15.35, P<0.001\right)$ in comparison to $24 \%$ in Pod Kopište lizards and $2 \%$ in Zagreb lizards 386 (Table 2).

387 Relative intestinal masses were heavier in lizards from Pod Kopište (3.6\% of total body 388 mass) and Pod Mrčaru (3.3\%) than in lizards from Zagreb (2.4\%; ANCOVA Population:

$389 F_{2,18}=9.53, P<0.007$; body mass: $F_{1,15}=6.94, P<0.030$, model run without interaction term as it 390 was non-significant; Fig. 3). We found no significant differences in gut length $\left(F_{2,36}=2.55\right.$, $391 P=0.092$ ) among the three populations. Regional intestinal masses (i.e.: PI, MI, H) did not differ 392 by population nor covary with lizard body mass. (See Supplemental Table S2 for values.) Mass 393 of total gut contents did not vary significantly (ANCOVA with body mass as covariate, $F_{2}, 18=$ $3942.10, P=0.163$ ) among the three populations. Gut contents were evenly distributed throughout the 395 PI, MI, and H. None of the populations retained more contents in a particular gut region than did 396 the other two populations, excepting the higher mass of digesta in the Pod Mrčaru lizards' 397 stomachs, mentioned above. Additionally, we observed nematodes in the HC of multiple lizards 398 from each of the three populations.

399 The epithelial surface magnifications (ESM) were not different in Pod Kopište versus 400 Pod Mrčaru lizards in any gut regions (Fig. 4). As such, the following reported values are pooled 401 across the two populations. The mucosa of the proximal intestine was $6.26 \pm 0.33$ x serosa $402(t=0.82, P=0.44)$. This ratio decreased distally along the gut: the mid intestine, $3.63 \pm 0.33 \mathrm{x}$ 403 serosa $(t=-0.14, P=0.89)$, a proximal part of the hindgut, $2.44 \pm 0.32 \times$ serosa $(t=0.64, P=0.54)$, 404 and more distal portions of the hindgut $(\mathrm{H}+), 1.95 \pm 0.24 \times \operatorname{serosa}(t=1.86, P=0.11)$. Figure 4 also 405 shows representative sections. We did not identify any qualitative differences between the cross 
sections of either population, including not identifying any valves captured in the histological

407 sections.

408

409 Digestive Enzyme Activities

410 Carbohydrases - We measured the majority of population differences in carbohydrate activities

411 in H or HC tissues. The newly omnivorous Pod Mrčaru lizards showed greater amylase activity,

412 but no other increases in plant-related enzyme activities compared to the Pod Kopište source

413 population.

414

The mass-specific $\alpha$-amylase activity in the hindgut contents was almost 6-fold higher in

415 Pod Mrčaru lizards compared to that measured in the Pod Kopište population $(t=-0.27, P=0.038$,

416 Fig. 5a, Supplemental Table S3). Amylase activity was undetectable in all but one HC sample

417 from the Zagreb population. We found no other differences in amylase activity. In most MI and

418 H samples, amylase activity was undetectable or replicates were too variable for confident

419 analyses. No other gut region nor pancreas showed differences in amylase activity among the

420 three populations (Pancreas: $F_{2,23}=2.97, P=0.072$; PI: $F_{2,10}=3.41, P=0.074$; PIGC: $F_{2,14}=0.49$,

$421 P=0.626$; MIGC: $\left.F_{2,13}=0.63, P=0.549\right)$, nor did we find any significant differences in the total gut

$422 \alpha$-amylase activity among populations $\left(F_{2,10}=2.05, P=0.180\right)$.

423 The total $\beta$-glucosidase activity was $>2.5$-fold higher in the Pod Mrčaru and Pod Kopište

424 lizards compared to the Zagreb lizards $\left(F_{2,17}=13.38, P=0.003\right.$; Fig. 6a). Mass specific $\beta$ -

425 glucosidase activity was nearly double in the PI of Pod Mrčaru and Pod Kopište lizards

426 compared to the Zagreb lizards $\left(F_{2,15}=14.33, P<0.001\right.$; Supplemental Table S3). We found no

427 other differences in regional $\beta$-glucosidase activities among the populations (Fig. 5b). Within

428 individuals, $\beta$-glucosidase activity was significantly higher in the PI and HC regions in 
429 comparison to some regions (e.g. MI, PIGC, etc; Fig. 5b; Pod Kopište: $F_{5,29}=8.02, P<0.001$; Pod

430 Mrčaru: $\mathrm{F}_{5,28}=11.7, P<0.001$; Zagreb: $\left.\mathrm{F}_{5,25}=3.433, P=0.017\right)$. This pattern appeared in all three

431 populations but was most pronounced in the two island populations. $\beta$-galactosidase activity

432 patterns throughout the gut were distinct from those of $\beta$-glucosidase activity (e.g. with $\beta$ -

433 galactosidase activity spiking in the PIGC and MI gut regions whereas we found the opposite

434 pattern with $\beta$-glucosidase activity). See Supplemental Table S3 for $\beta$-galactosidase activity

435 measures and Supplemental Fig. S2 for a comparison of the regional activities of these two

436 enzymes.

437 Neither regional mass specific nor total maltase activities $\left(F_{2,17}=2.28, P=0.133\right)$ were

438 different among the three populations (Fig. 5c). In the PI of the Pod Kopište lizards, the N-

439 acetyl- $\beta$-D-glucosaminidase (NAG) activity was $2 \mathrm{x}$ greater than in the PI of the Pod Mrčaru and

440 Zagreb populations $\left(F_{2,15}=5.87, P=0.013\right.$; Supplemental Table S3). There were no other regional

441 differences among the populations (Fig. 5d), including total NAG activity. In the Pod Mrčaru

442 and Zagreb populations, the greatest NAG activity was found in the HC compared to any other

443 region $\left(F_{5,50}=23.60, P<0.001\right.$; Pod Mrčaru and Zagreb populations pooled due to low sample

444 sizes for PIGC and H regions).

445 In both the $\mathrm{H}$ and $\mathrm{HC}$, the Pod Kopište population had lower regional trehalase activity

446 than one of the other two populations (Fig. 5e). Still, there were no population differences in

447 trehalase activity in more proximal regions, nor in total activity of the enzyme (Supplemental

448 Table S3). The Pod Mrčaru population's H trehalase activity $(0.058 \pm 0.020 \mu \mathrm{mol}$ glucose

449 liberated $\left.\min ^{-1} \mathrm{~g}^{-1}\right)$ was higher than the $\mathrm{H}$ activity in the Pod Kopište population $(0.0045 \pm 0.003$

$450 \mu \mathrm{mol}$ glucose liberated $\left.\min ^{-1} \mathrm{~g}^{-1} ; F_{2,9}=5.50, P=0.024\right)$. The Zagreb population's HC activity 
$451\left(0.254 \pm 0.134 \mu \mathrm{mol}\right.$ glucose liberated $\left.\min ^{-1} \mathrm{~g}^{-1}\right)$ was higher than Pod Kopište HC activity

$452\left(0.025 \pm 0.011 \mu \mathrm{mol}\right.$ glucose liberated $\left.\min ^{-1} \mathrm{~g}^{-1} ; F_{2,12}=4.28, P=0.041\right)$.

453

454 Proteases - Protease activity differed by population, but not along the diet lines we predicted.

455 In the HC, the mass specific trypsin activity was >5-fold higher in the Pod Mrčaru

456 population than in the Pod Kopište population $\left(F_{2,11}=5.33, P=0.024\right.$; Fig. 5f, Supplemental Table

457 S3). The trypsin activity in the HC of the Zagreb population (Supplemental Table S3) was not

458 different from the other two populations. No other gut region showed differences in activity

459 among the three populations (Fig. 5f), nor did we find difference in the total trypsin activity

460 among populations. The mass specific trypsin activity in the pancreas was $>2.5 \mathrm{x}$ higher in Pod

461 Kopište and Pod Mrčaru lizards $\left(0.454 \pm 0.050 \mu \mathrm{mol}\right.$ p-nitroaniline released $\left.\min ^{-1} \mathrm{~g}^{-1}\right)$ than in the

462 pancreases of Zagreb lizards $\left(0.190 \pm 0.040 \mu \mathrm{mol} p\right.$-nitroaniline released $\min ^{-1} \mathrm{~g}^{-1} ; \mathrm{P}: F_{2,23}=5.14$, $463 P=0.014$, Fig. 7).

464 The total aminopeptidase activity throughout the gut (Fig. 6b) was nearly 2.5-fold higher 465 in the Zagreb population than in the Pod Kopište population $\left(\mathrm{F}_{2,17}=7.23, \mathrm{P}=0.005\right.$; Supplemental 466 Table S3), although neither differed from the Pod Mrčaru population. Compared to the island 467 lizards, the Zagreb population had a >32-fold higher mass specific aminopeptidase activity in 468 PIGC $\left(F_{2,12}=14.58, P<0.001\right)$, as well as higher (although not quite as pronounced) activities in

$469 \mathrm{MI}\left(F_{2,17}=15.14, P<0.001\right)$ and $\operatorname{MIGC}\left(F_{2,12}=12.33, P<0.001\right)$ tissues (Fig. 5g).

471 Lipase-There was no difference in lipase activity across the three lizard populations

472 (Supplemental Fig. S3 and Table S3; total lipase $F_{2,18}=0.879, P=0.432$ ). 
475 Microbial fermentation was considerably lower in the newly omnivorous Pod Mrčaru lizards.

476 The Pod Kopište $P$. siculus had concentrations of $61.90 \pm 4.90 \mathrm{mM}$ of total SCFA concentrations

477 in their HC, $>3 x$ higher than the $19.20 \pm 8.60 \mathrm{mM}$ in Pod Mrčaru lizards $(t=6.42, P=0.001$, Table

478 3). This phenomenon was primarily due to nearly four-fold higher total acetate $(t=9.06, P<0.001)$

479 and total isobutyrate $(t=3.80, P<0.001)$ in the Pod Kopište population compared to Pod Mrčaru

480 lizards. However, even with these two SCFAs omitted, non-significant increases in propionate,

481 butyrate, and valerate (but not isovalerate) contributed to significantly increased total SCFA

482 concentrations $(t=4.00, P=0.010)$ in the hindguts of the Pod Kopište lizards. When considered as

483 a proportion of the total SCFAs within individuals, only the acetate concentration was higher in

484 the Pod Kopište lizards (Table 3; $t=2.17, P=0.049$ ). Although total SCFAs were lower in the Pod

485 Mrčaru population, isobutyrate $(t=-2.74, P=0.041)$ and isovalerate $(t=-4.76, P=0.005)$ were

486 higher proportionally.

487 The Zagreb individual we measured had very low concentrations of all SCFAs, only 0.60

$488 \mathrm{mM}$ total. Overall, the proportions of each SCFA (e.g. acetate, isobutyrate, etc.) measured in the

489 Zagreb lizard were intermediate to the SCFA proportions found in the island lizards, excepting

490 the nearly absent valerate concentration.

491

492 Organic Matter Digestibility

493 The newly omnivorous Pod Mrčaru lizards were better at digesting plants than were the lizards

494 of the Pod Kopište source population. At 61\% OM digestibility, the Pod Mrčaru lizards had 1.1x

495 higher organic matter digestibility (by mass) than the Pod Kopište lizards (55\% OM digestibility)

496 on the herbivore diet (Fig. 8, Supplemental Table S4; ANCOVA: population $F_{1,6}=6.17, P=0.048$, 
497 body mass $\left.F_{1,6}<0.001, P=0.983\right)$. On an omnivore diet, Pod Mrčaru lizards had an almost $4 \%$

498 higher organic matter digestibility than their Pod Kopište counterparts (ANCOVA: population $499 \quad F_{1,7}=5.875, P=0.0458$; body mass $F_{1,7}=3.065, P=0.1235$ ). The two populations did not differ in

500 digestibility of an all insect diet (ANCOVA: population $F_{1,7}=0.670, P=0.440$, body mass

$\left.501 \quad F_{1,7}=0.619, P=0.457\right)$. For all three diets, analyses using other covariates are available in

502 Supplemental materials. Final and percent change in body masses and SVL are available in 503 Supplemental Table S1.

505 Discussion

507 Subtle changes in performance

508 The P. siculus of Pod Mrčaru eat more plants than their Pod Kopište counterparts after $\sim 35$ years 509 of divergence (Herrel et al. 2008) and their digestibility performance has shifted. Overall, the 510 newly omnivorous Pod Mrčaru population was slightly better able to digest plant material in the

511 laboratory than the Pod Kopište lizards, and this difference is supported by subtle changes in gut

512 function. Our expectations of gut-wide shifts in form and function based on the framework of the

513 AMH and other theoretical considerations (Table 1) were not supported, and thus, we largely

514 accept the null hypothesis of little differences in gut function. Indeed, the potential mechanisms

515 (i.e., slight differences in hindgut amylase and trypsin activity; Fig. 5) underlying the increase in 516 digestibility of plant material are subtle and localized within the hindgut. These results are more 517 consistent with Pod Mrčaru lizards — and perhaps even Pod Kopište P. siculus — as facultative 518 omnivores (Herrel et al. 2004), agreeing with the greater plant intake by the Pod Kopište $P$. 
519 siculus observed in this study (24\% of gut content mass) than in the past (4-7\%; Herrel et al.

520 2008).

521 As reviewed across vertebrate taxa by Leigh and colleagues (2018a), shifts to high

522 protein diets often lead to higher protease activities, yet show mixtures of increases and

523 decreases in carbohydrases, but no changes in lipases. Shifts to lower protein diets, such as to a

524 plant-rich diet (e.g. like in the Pod Mrčaru lizards) yielded more erratic results in digestive

525 enzyme activities with both increases and decreases in proteases, carbohydrases, and lipases. In

526 the $P$. siculus system, we found both increases and decreases in carbohydrases, and an increase

527 in a protease with the Pod Mrčaru lizards' shift to a plant-rich diet. Yet, all of the studies

528 reviewed by Leigh et al. (2018a) considered animals in feeding experiments on shorter time

529 scales (weeks to months), not wild individuals following a natural dietary shift over decades.

530 As the majority of endogenous nutrient digestion and absorption in non-ruminant

531 vertebrates occurs in the proximal portion of the intestine (Vonk and Western 1984; Karasov and

532 Martínez del Rio 2007; Le et al. 2019), differences in the structure and function of the hindgut

533 point to differences in the function of microbial symbionts in this gut region (McBee and McBee

534 1982; Bergman 1990; Bjorndal 1997). According to the plug flow reactor model of digestion

535 (Penry and Jumars 1986, 1987; Karasov and Hume 1997; Stevens and Hume 2004), nutrients are

536 digested and absorbed down their gradient as they flow through the gut. Thus, a shift in gut

537 function in the proximal region will promote downstream changes, from more potential digestion

538 to more opportunities for nutrient absorption. For example, an increase in trypsin activity in the

539 proximal intestine could lead to greater digestion of proteins into dipeptides that can serve as a

540 substrate for aminopeptidase in the mid intestine and hindgut. There is subsequently more gut

541 remaining over which the dipeptides can be absorbed. Changes in the lizard hindgut, therefore, 
542 may represent a small portion of overall nutrient acquisition. For example, the hindgut of two

543 iguanids (Dipsosaurus dorsalis and Sauromalus ater) showed $<5 \%$ of the transport capacity of

544 D-Glucose and L-Proline (a non-essential amino acid) in comparison to the proximal intestine in

545 these species (Karasov et al. 1985). The mammalian large intestine is also known as a site for

546 ion, water, SCFA, and amino acid absorption, particularly essential amino acids (e.g., lysine)

547 (with SCFA and essential amino acids coming from microbial sources; Stevens and Hume 1998;

548 van der Wielen et al. 2017; Moran et al. 2019). Hence, the L-Proline absorption measured in

549 Karasov et al. (1985) may not be representative of all amino acid absorption in the lizard

550 hindgut, as there are separate transporters for charged amino acids (Karasov and Martinez del

551 Rio 2007; van der Wielen et al. 2017), like lysine, which also appears to be an essential amino

552 acid for reptiles (Herbert and Coulson 1976).

553 Even though the Pod Mrčaru lizards digested plant material organic matter $\sim 10 \%$ better

554 than the Pod Kopište lizards, the functional differences we were able to detect amongst $P$. siculus

555 populations were localized to the hindgut. Based on these differences, we may infer that

556 microbial communities, generally localized to the hindgut, play a role in these differential

557 abilities (Karasov and Douglas 2013; Moran et al. 2019). Interestingly, modest shifts in the

558 hindgut microbial communities of the Pod Mrčaru and Pod Kopište lizards included more of the

559 Archaean, Methanobrevibacter, in the Pod Mrčaru lizards (Lemieux-Labonté et al., Unpubl

560 data), and these taxa can affect the digestive function, especially of glycans and protein (Samuel

561 and Gordon 2006; Mathur et al., 2013). A study of the microbiome of the Croatian lizards is

562 nearing publication (Lemieux-Labonté et al., Unpubl data).

563 Between the new and source populations of lizards, Pod Mrčaru and Pod Kopište, the

564 only functional difference we measured outside of the hindgut was higher NAG activity in the 
565 proximal intestines of Pod Kopište lizards. Higher NAG activity could contribute to the digestion

566 of chitin from arthropods carapaces, and the cell walls of fungi and nematodes (Skoczylas 1978;

567 Vonk and Western 1984). Although we expected patterns of NAG activity to conform to that of

568 brush border digestive enzymes (German et al. 2015), NAG activity was the highest in the HC,

569 consistent with microbial synthesis, not endogenous synthesis in lizard tissue (Jhaveri et al.

570 2015). Moreover, $P$. siculus appears to have considerably lower endogenous NAG activity

571 compared to other lizards (Table 4; Jeuniaux 1961, 1963; Marsh et al. 2001).

572 As we had predicted that the Pod Mrčaru lizards would rely on fermentative pathways to

573 digest their plant-material rich diet, the higher SCFA concentrations in Pod Kopište lizards were

574 opposite of what we expected. Higher SCFA concentrations are an indication of more microbial

575 fermentation (Bjorndal 1997; Pryor and Bjorndal 2005). Indeed, high acetate, propionate,

576 isobutyrate, and butyrate are all associated with fermentation of plant material. Surprisingly, the

577 acetate and isobutyrate concentrations and ratios of total SCFAs were higher in the Pod Kopište

578 lizards. In a study of Uromastyx aegyptius (Foley et al. 1992), a strict herbivore, acetate,

579 propionate, and butyrate concentrations were similar to our measurements in the Pod Kopište $P$.

580 siculus, suggesting that the insectivorous lizards of this study can employ fermentative digestion

581 more than expected. In the U. aegyptius study, Foley and colleagues noted that $>98 \%$ of the

582 SCFAs they measured in the hindgut were then absorbed prior to defecation. Similarly, we

583 assume our measurements are indicative of SCFA production in the hindgut and not lower SCFA

584 absorption rates in Pod Kopište lizards, but this assumption should be tested.

585 A potential explanation for lower levels of fermentation in the Pod Mrčaru lizards lies

586 with intake and transit time (Stevens and Hume 1998; Macfarlene and Macfarlene 2003). Lower

587 quality food leads to higher intake, and higher intake leads to faster gut transit rates (Dadd 1960; 
Pritchard and Robbins 1990; Diamond 1991; Horn and Messer 1992; Fris and Horn 1993; Castle

589 and Wunder 1995; Karasov and Martinez del Rio 2007). One of the keys of microbial

590 fermentation is that microbes need time to digest insoluble fiber, eventually producing SCFAs

591 (Bergman 1991; Stevens and Hume 1998; Macfarlene and Macfarlene 2003). Animals that are

592 reliant on fermentation to make a living on plant material have ways (e.g., hindgut chambers in

593 iguanas, rumens of cattle) to slow gut transit rates to allow microbes the time they need (Stevens

594 and Hume 1998, 2004). With 2.2x greater stomach content masses than Pod Kopište lizards, Pod

595 Mrčaru lizards likely have higher intake of their lower quality food. Thus, the lower SCFA

596 concentrations in Pod Mrčaru lizards could reflect gut transit rates that are too fast for adequate

597 fermentation in the hindgut. The hindgut valves themselves may have arisen to slow transit of

598 material in the hindgut, but the extent to which the valves act as baffles should be examined.

599 Furthermore, hindgut microbes can play roles other than fermentation in terms of aiding the host

600 in the digestive process (e.g., amino acid and vitamin synthesis; Moran et al. 2019). In fact, the

601 slight differences in organic matter digestibility among the Pod Mrčaru and Pod Kopište lizards

602 argues against significant fiber digestion in the Pod Mrčaru lizards, but fiber digestibility should

603 be measured in these lizards. It should be noted that we attempted to measure cellobiohydrolase

604 activities in P. siculus, but detected no activity anywhere in their guts.

605 Although hindgut valves are present in Pod Mrčaru hindguts (Herrel et al. 2008; Vervust

606 et al. 2010; Wehrle 2018), we did not observe differences in epithelial magnification by

607 population. For whatever reason, the Pod Mrčaru lizards we examined for hindgut valves

608 histologically in summer $2013(n=3)$ did not have clear epithelial folds (valves) in their hindguts.

609 This stands in contrast to all other Pod Mrčaru lizards ( $n=28$, spanning four seasons over three

610 additional years) we examined, which had clearly identifiable folds in the proximal to mid 
611 portion of their hindgut, dividing the gut in the transverse plane (Supplemental Fig. S4; Wehrle

612 2018). The Pod Kopište lizards ( $n=29)$ lacked these valves entirely. The same methods were used

613 across years, so there were no methodological differences. These data, combined with those from

614 Herrel et al. (2008) and Vervust et al. (2010) convince us that, although usually present, the

615 hindgut valves in P. siculus may be flexible in their morphology or even presence, and they are

616 not fixed features in the Pod Mrčaru lizards. The general pattern of surface area decreasing along

617 the gut (i.e.: PI>MI>H, Fig. 4) was consistent with our expectations (Skoczylas 1978; Stevens

618 and Hume 2004) considering we did not observe the valves in our sections from summer 2013

619 (even the $\mathrm{H}+$ sections).

620 Whereas shifts in gut structure and function in wild lizards may be the result of plasticity

621 due to dietary differences, the Pod Mrčaru lizards' higher digestibility of a plant diet (including

622 the omnivore diet) in the laboratory support their ability to make a living on a plant-rich diet. It is

623 possible that a lifetime of acclimation to their respective wild diets has influenced digestive

624 performance, and this may be mediated through the microbiome of the hindgut (i.e., not

625 necessarily an evolved difference in the lizards themselves; Garland and Adolph 1991).

626

627 Lizard Digestive Physiology

628 Digestive physiology in reptiles has been less studied than in other taxa such as mammals and

629 fishes (Karasov et al. 1985; Stevens and Hume 2004; Kohl et al. 2016b), particularly in wild

630 populations. We included the Zagreb population of $P$. siculus to give context to the magnitude of

631 differences between the Pod Mrčaru and Pod Kopište populations, and identify which structural

632 and physiological characteristics are unlikely to change (e.g., gut length) even between distantly

633 related populations; the Zagreb population is not as closely related to the island populations as 
634 the island populations are to each other (Podnar et al. 2005; Herrel et al. 2008). We predicted that

635 the Pod Kopište and Zagreb populations, which both mostly consume invertebrates, would show

636 the most similarity in gut form and function. However, we found that the closely related island

637 populations show greater similarities in gut form and function than do the insectivorous

638 populations. Sagonas and colleagues (2015) found more similarities in the gut physiology and

639 morphology of lizards with more similar habitats (i.e. insular vs. mainland) than populations that

640 had more similar diets. Indeed, island effects on physiology, morphology, and ecology often

641 outweigh other factors in lizards, including effects on diet (Van Damme 1999; Cooper and Vitt

642 2002; Spiller et al. 2010) and digestion (Pafilis et al. 2007; Vidal and Sabat 2010; Sagonas et al.

643 2015). It may also be that the shared evolutionary history of the Pod Mrčaru and Pod Kopište

644 lizards leads to their similarity in gut structure and function (Garland and Adolph 1994; Karasov

645 and Martinez del Rio 2007).

646 The more massive guts of the Pod Mrčaru and Pod Kopište lizards compared to the

647 outgroup Zagreb population suggest that the new and source population lizards allocate more

648 tissue resources to digestion. Exactly why this is the case remains unknown. The Zagreb lizards

649 live in an urban area with copious plant cover and potential food sources, whereas the Pod

650 Kopište and Pod Mrčaru lizards live on small, densely populated islets that are likely

651 challenging, from space and resource perspectives (Herrel at el. 2008). Aminopeptidase was the

652 only digestive enzyme that showed higher activity in the Zagreb population in comparison to the

653 Pod Kopište and Pod Mrčaru lizards. The elevated aminopeptidase activity, which was within the

654 range measured in other lizards (Table 4) may compensate for the Zagreb population's lower gut

655 tissue mass, leading to similar nutrient acquisition outcomes for protein among the populations. 
656 Interestingly, the elevated aminopeptidase activities of the PIGC in the Zagreb lizards suggests

657 inherent aminopeptidase activity in their ingested prey (mostly ants).

658 Still, as more than two-thirds of the enzymatic differences we identified were between

659 island and outgroup, and not between the two recently diverged island populations, it appears

660 that endogenous enzyme activities are not as flexible amongst the island populations, despite the

661 dietary differences among them. Feeding behavior and microbial symbionts may dampen

662 selection on the digestive system, as changes in behavior can offset evolutionary changes in

663 physiology and morphology (Sibley 1981; Huey et al. 2003; Clements and Raubenheimer 2006).

664 By increasing food intake and through shifts in microbiome function (Lemieux-Labonté et al.,

665 Unpubl data), Pod Mrčaru lizards may not need to dramatically shift their gut function to digest

666 plant material more efficiently.

667

Amylase, trypsin, and lipase activities were highest in the pancreas (Figure 7) and

668 decreased distally along the gut, patterns consistent with pancreatic enzymes (Fig. 2; Stevens and

669 Hume 2004; Clements and Raubenheimer 2006; German et al. 2015). We predicted brush border

670 enzymes would peak in the mid intestine, consistent with dimer (substrate) concentrations being

671 highest in the mid intestine following polymer degradation in the proximal intestine. This pattern

672 is seen in other vertebrates (Fig. 2; Vonk and Western 1984; Stevens and Hume 2004; German et

673 al. 2015), yet in the lizards of this study, maltase and trehalase were more active proximally in

674 the gut. Trehalose - the substrate for trehalase - is, of course, a disaccharide as it is ingested, and

675 maltose — the substrate for maltase — may also be more available proximally from rapid starch

676 digestion (Sibley 1981; German and Bittong 2009; Karasov and Douglas 2013; German et al.

677 2015). 
679 non-avian reptile has been recorded to produce endogenous $\beta$-glucosidases in their digestive

680 tracts (Stevens and Hume 2004; Karasov and Douglas 2013), and thus must rely on microbial

681 symbionts to produce this enzyme for digesting breakdown products of cellulose (e.g.,

682 cellobiose). As predicted, $P$. siculus has a spike of $\beta$-glucosidase activity in the HC, consistent

683 with microbial synthesis (Fig. 2; German et al. 2015; Leigh et al. 2018b). However, the $\beta$ -

684 glucosidase activity is just as high in the PI as in the HC. Of interest, the high activity in the PI,

685 and as a result, higher total $\beta$-glucosidase activity, is most starkly found in the island

686 populations, with present, but much diminished activity observed in the mainland lizards. A $\beta$ -

687 glucosidase is present in the Anolis carolinensis genome (on chromosome 5; ensembl.org), and

688 one is expressed in the intestinal tissues of the herbivorous fish Cebidichthys violaceus (Heras et

689 al. 2020), but it remains unknown if this enzyme is expressed in the digestive system of $P$.

690 siculus, and liver, as in mammals (de Graaf et al. 2001; Hayashi et al. 2007). Overall, these

691 patterns suggest that $P$. siculus may produce $\beta$-glucosidase endogenously in the gut or acquire it

692 from the enteric microbiome in the PI in addition to in the HC. Kohl and colleagues (2016a)

693 propose that $\beta$-galactosidase, known to be endogenously produced in reptiles (on chromosome 1

694 in the A. carolinensis genome; ensebl.org), is active against $\beta$-glucosidase substrates. Still, the $\beta$ -

695 galactosidase activity patterns we measured varied from the $\beta$-glucosidase activity patterns

696 throughout the gut (Supporting information Figure S2). Thus, there is some evidence that $P$.

697 siculus may endogenously produce $\beta$-glucosidase or house $\beta$-glucosidase producing microbes in

698 their PI. We acknowledge that $\beta$-glucosidase may have functions outside of digestion in the

699 intestine (e.g. in lysosomes), but this increased activity in the PI opposed to other intestinal 
700 tissues is suggestive of digestive function. The mechanisms and function of this finding warrant

701 further investigation to tease apart these possibilities.

702

703 Conclusions, Potential Limitations, and Future Directions

704 The P. siculus system offers a rare opportunity to observe a natural diet shift in wild populations,

705 and the subsequent digestive responses. Few studies investigate animals' digestive physiology on

706 a natural diet, within their ecosystem. In this newly omnivorous population of lizards, the only

707 detectible changes in gut form and function - including valves (presence or absence), enzyme

708 activity, and microbial fermentation — start from the hindgut. Although we know the Pod Mrčaru

709 lizards have changed their body morphology over ecological time (Herrel et al. 2008), any shifts

710 in their digestive physiology appears to be more constrained on this timescale, or mitigated by

711 differences in behavior and ecology. We currently do not know whether the observed changes

712 represent flexibility (Piersma and Drent 2003), or evolved differences with underlying genetic

713 changes (Garland and Adolph 1991). Some dietary shifts may not be as limited by physiology as

714 they are by these animals' ecology. Future investigations in this system should focus on

715 microbiome function. Moreover, as the stomach can play a major role in the digestive process,

716 and can account for greater than 50\% of gut transit time (Karasov and Martínez del Río 2007),

717 more work on gastric function is warranted, and is the subject of our own work on this system.

718 We do recognize that this study can be mistaken as a "two species comparison", which

719 comes with caveats and cautions (Garland and Adolph 1994), especially when comparing the

720 island populations with the mainland population in Zagreb. However, most of our work is

721 focused on comparing the two island populations, which according to their 16s rRNA sequences,

722 have not diverged much genetically over 30+ years of separation (Herrel et al. 2008). The 
723 similarity among the two island populations may, thus, simply represent that they are still very

724 much the same taxon phylogenetically, and thus, may not be treated as separate entities (Karasov

725 and Martínez del Río 2007). The similarity of the Pod Mrčaru and Pod Kopište lizards in

726 comparison to the Zagreb population, should, therefore, not be surprising given the short period

727 of time of the island populations' separation (Nevo 1972; Herrel et al. 2008). Similar results

728 among populations of insular vs mainland populations of lizards have been observed in other

729 species (Pafilis et al. 2007; Sagonas et al. 2015). Nevertheless, the greater plant organic matter

730 digestibility displayed by the Pod Mrčaru lizards shows that they have indeed achieved

731 mechanisms for digesting plant material, and our work suggests such an ability derives from the

732 hindgut.

733

734 Author Contributions

735 BAW, DPG, AH, and ZT designed the experiment. BAW, AH, and DPG performed the 736 fieldwork. BAW, B-Q N-P, SM, RKD, RA, and DPG conducted the lab work. BAW analyzed

737 the data. BAW and DPG led the writing of the manuscript. All authors contributed critically to

738 the drafts and gave final approval for publication.

739

740 Acknowledgements

741 We are indebted to Park Prirode Lastovsko otočje and the people of Lastovo for logistical

742 support, transportation, and permission to collect lizards on the Croatian islands. We thank K.

743 Chernoff, A.-C. Fabre, and M. Krajnović for assistance in the field, A. Kokanouteanon and S.

744 Huynh for help with sample preparation, L. Dobson for GIS work, and R. Hamersley for

745 equipment use. All lizard collection to euthanasia was conducted under approval of the 
746 Institutional Care and Use Committee (IACUC) at University of California, Irvine, protocol

747 \#2013-3096. Lizards were collected under permission from the Croatian government, permit

748 \#517-07-1-1-1-13-2. This study was funded by NSF CNIC grant IIA-1318059 to DPG, CNRS

749 funding to $\mathrm{AH}$, and Undergraduate Research grants to RA, RKD, and SM from the University of

750 California, Irvine. The authors acknowledge that much of this work was done on the occupied

751 and unceded land of the Tongva Nation, where UC Irvine is located. We deeply appreciate the

752 feedback from four anonymous reviewers and K.D. Kohl that helped to improve this manuscript.

753

754 Data Accessibility

755 Data are available at http://german.bio.uci.edu/Supplements.html. 


\section{Literature Cited}

Bell T., D. Ager, J.-I. Song, J.A. Newman, I.P. Thompson, A.K. Lilley, and C.J. van der Gast. 2005. Larger islands house more bacterial taxa. Science 308:1884. doi: 10.1126/science. 1111318

Bergman E.N. 1990. Energy contributions of volatile fatty acids from the gastrointestinal tract in various species. Physiol Rev 70:567-590. doi: 10.1152/physrev.1990.70.2.567

Bignell D.E. 1984. The arthropod gut as an environment for microorganisms. In Anderson JM, Rayner ADM, and Walton DWH (Eds.), Invertebrate-Microbial Interactions (pp. 205-227) Cambridge, UK: Cambridge University Press.

Bjorndal K.A. 1989. Flexibility of digestive responses in two generalist herbivores, the tortoises Geochelone carbonaria and Geochelone denticulata. Oecologia 78:317-321. doi: doi.org/10.1007/BF00379104

Bjorndal K.A. 1997. Fermentation in reptiles and amphibians. In Mackie R and White B (Eds.), Gastrointestinal Microbiology, volume 1: Gastrointestinal ecosystems and fermentations (pp. 199-230). New York, NY: Chapman and Hall.

Buddington R.K., J.W. Chen, and J. Diamond. 1987. Genetic and phenotypic adaptation of intestinal nutrient transport to diet in fish. J. Physiol 393: 261-281. doi: 10.1113/jphysiol.1987.sp016823

Caviedes-Vidal E., D. Afik, C. Martinez del Rio C, and W.H. Karasov. 2000. Dietary modulation of intestinal enzymes of the house sparrow (Passer domesticus): testing an adaptive hypothesis. Comp Biochem Physiol A Mol Integr Physiol 125:11-24 doi: 10.1016/s1095-6433(99)00163-4

Castle K.T. and B.A. Wunder. 1995. Limits to food intake and fiber utilization in the prairie vole, Microtus ochrogaster: effects of food quality and energy need. J. Comp Phys B 164:609-6117. doi: 10.1007/BF00389801

Christel C.M., D. DeNardo, and S.M. Secor. 2007. Metabolic and digestive response to food ingestion in a binge-feeding lizard, the Gila Monster (Heloderma suspectum). JEB 210:3430-3439. doi:10.1242/jeb.004820

Clements K.D and D. Raubenheimer. 2006. Feeding and nutrition. In: Evans DH (Ed.), The physiology of fishes (pp. 47-82). Boca Raton, FL: CRC Press

Cooper W.E. and L.J. Vitt. 2002. Distribution, extent, and evolution of plant consumption by lizards. J Zool 257:487-517. doi: 10.1017/S0952836902001085

Dadd R.H. 1960. Observations on the palatability and utilization of food by locusts, with particular reference to the interpretation of performances in growth trials using synthetic diets. Entomologia Experimentalis Et Applicata 3:282-304. doi: 10.1111/j.15707458.1960.tb00458.x

Dearing M.D. 1993. An alimentary specialization for herbivory in the tropical whiptail lizard Cnemidophorus murinus. Journal of Herpetology 27:111-114. doi: 10.2307/1564920

de Graaf M., I.C. van Veen, I.H. van der Meulen-Muileman, W.R. Gerritsen, H.M. Pinedo, and H.J. Haisma. 2001. Cloning and characterization of human liver cytosolic beta-glycosidase. Biochem. J., 356:907-910. doi: 10.1042/bj3560907

Diamond J.M. 1991. Evolutionary design of intestinal nutrient absorption - enough but not too much. News in Physiological Sciences 6:92-96. doi: 10.1152/physiologyonline.1991.6.2.92

Espinoza R.E., J.J. Wiens, and C.R. Tracy. 2004. Recurrent evolution of herbivory in small, cold-climate lizards: breaking the ecophysiological rules of reptilian herbivory. 
Proceedings of the National Academy of Sciences, USA 101:16819-16824. doi: 10.1073/pnas.0401226101

Fris M.B. and M.H. Horn. 1993. Effects of diets of different protein content on food consumption, gut retention, protein conversion, and growth of Cebidichthys violaceus (Girard), an herbivorous fish of temperate zone marine waters. J Exp Mar Biol Ecol 166: $185-202$

Foley W.J., A. Bouskila, A. Shkolnik, and I. Choshniak. 1992. Microbial digestion in the herbivorous lizard Uromastyx aegyptius (Agamidae). J Zool 226:387-398. doi: 10.1111/j.1469-7998.1992.tb07486.x

Garland, Jr., T., and S.C. Adolph. 1991. Physiological differentiation of vertebrate populations. Annual Review of Ecology and Systematics 22:193-228. doi: 10.1146/annurev.es.22.110191.001205

Garland, Jr., T., and S.C. Adolph. 1994. Why not to do two-species comparative studies: limitations on inferring adaptation. Physiological Zoology 67:797-828. doi: 10.1086/physzool.67.4.30163866

German D.P. 2009. Inside the guts of wood-eating catfishes: can they digest wood? J Comp Physiol B, 179:1011-1023. doi: 10.1007/s00360-009-0381-1

German D.P. 2011. Digestive efficiency. In Encyclopedia of Fish Physiology: From Genome to Environment (ed. Farrel A.P.), pp. 1596-1607. San Diego, Academic Press

German D.P. and R.A. Bittong. 2009. Digestive enzyme activities and gastrointestinal fermentation in wood-eating catfishes. J Comp Physiol B 175:1025-1042. doi: 10.1007/s00360-009-0383-z

German D.P., M.H. Horn, A. Gawlicka. 2004. Digestive enzyme activities in herbivorous and carnivorous prickleback fishes (Teleostei: Stichaeidae): ontogenetic, dietary, and phylogenetic effects. Physiol Biochem Zool 77:789-804 doi.org/10.1086/422228

German D.P., B.C. Nagle, J.M. Villeda, A.M. Ruiz, A.W. Thomson, S. Contreras-Balderas, and D.H. Evans. 2010. Evolution of herbivory in a carnivorous clade of minnows (Teleostei: Cyprinidae): effects on gut size and digestive physiology. Physiol Biochem Zool 83:1-18 doi: $10.1086 / 648510$

German D.P., M.N. Weintraub, A.S. Grandy, C.L. Lauber, Z.L. Rinkes, and S.D. Allison. 2011. Optimization of hydrolytic and oxidative enzyme methods for ecosystem studies. Soil Biol Biochem 43:1387-1397 doi: 10.1016/j.soilbio.2011.03.017

German D.P., A. Sung, P.K. Jhaveri, and R. Agnihotri. 2015. More than one way to be an herbivore: convergent evolution of herbivory using different digestive strategies in prickleback fishes (family Stichaeidae). Zool 118:161-170 doi: 10.1016/j.zool.2014.12.002

German D.P., D.M. Foti, J. Heras, H. Amerkhanian, and B.L. Lockwood. 2016. Elevated gene copy number does not always explain elevated amylase activities in fishes. Physiol Biochem Zool 89:277-293 doi: 10.1086/687288

Godon J.J., P. Arulazhahan, J.-P. Steyer, and J. Hamlin. 2016. Vertebrate bacterial gut diversity: size also matters. BMC Ecology 16:12. doi: 10.1186/s12898-016-0071-2

Hall K.C. and D.R. Bellwood. 1995. Histological effects of cyanide, stress and starvation of the intestinal mucosa of Pomacentrus coelestis, a marine aquarium fish species. J Fish Biol 47:438-454 doi: 10.1111/j.1095-8649.1995.tb01913.x

Hayashi Y., N. Okino, Y. Kakuta, T. Shikanai, M. Tani, H. Narimatsu, and M. Ito. 2007. Klothorelated protein is a novel cytosolic neutral beta-glycosylceramidase. J Biol Chem 282:30889-30900. doi: 10.1074/jbc.M700832200 
Heras J., M. Chakraborty, J.J. Emerson, and D.P. German. 2019. Physiological genomics of dietary adaptation in a marine herbivorous fish. Proc Royal Soc B (Resubmitted) doi: $10.1101 / 457705$

Herbert J.D. and R.A. Coulson. 1976. Plasma amino acids in reptiles after feeding protein or amino acids and after injecting amino acids. J Nutr 106: 1097-1101 doi:10.1093/jn/106.8.1097

Herrel A., B. Vanhooydonck, and R. Van Damme. 2004. Omnivory in lacertid lizards: adaptive evolution or constraint? J Evol Biol 17:974-984 doi: 10.1111/j.1420-9101.2004.00758.x

Herrel A., R. Joachim, B. Vanhooydonck, and D.J. Irschick. 2006. Ecological consequences of ontogenetic changes in head shape and bite performance in the Jamaican lizard Anolis lineatopus. Biol J Linn Soc 89:443-454 doi: 10.1111/j.1095-8312.2006.00685.x

Herrel A., K. Huyghe, B. Vanhooydonck, T. Backeljau, K. Breugelmans, I. Grbac, R. Van Damme, and D.J. Irschick. 2008. Rapid large-scale evolutionary divergence in morphology and performance associated with exploitation of a different dietary resource. PNAS 105:4792-4795 doi: 10.1073/pnas.0711998105

Horn M.H., A.K. Gawlicka, D.P. German, E.A. Logothetis, J.W. Cavanagh, and K.S. Boyle. 2006. Structure and function of the stomachless digestive system in three related species of New World silverside fishes (Atherinopsidae) representing herbivory, omnivory, and carnivory. Marine Biology 149:1237-1245. doi: 10.1007/s00227-006-0281-9

Horn M.H. and K.S. Messer. 1992. Fish guts as chemical reactors: a model for the alimentary canals of marine herbivorous fishes. Mar Biol 113:527-535

Huey R.B., P.E. Hertz, and B. Sinervo. 2003. Behavioral drive versus behavioral inertia in evolution: a null model approach. Am Nat 161:357-366. doi: 10.1086/346135

Iglesias S., C.R. Tracy, G.S. Bedford, T.J. McWhorter, and K.A. Christian. 2009. Seasonal effects on intestinal enzyme activity in the Australian agamid lizard, Lophognathus temporalis. Comparative Biochemistry and Physiology B 153:89-94. doi: 10.1016/j.cbpb.2009.02.003

Iverson J.B. 1982. Adaptations to herbivory in iguanine lizards. In: Burghardt GM, Rand AS (Eds.), Iguanas of the world: Their behavior, ecology, and conservation (pp. 60-76). Park Ridge, New Jersey: Noyes Publications.

Jeuniaux C. 1961. Chitinase: an addition to the list of hydrolases in the digestive tract of vertebrates. Nature 192:135-136. doi: 10.1038/192135a0

Jeuniaux C. 1963. Chitine et chitinolyse. Masson, Paris.

Jhaveri P., Y. Papastamatiou, and D.P. German. 2015. Digestive enzyme activities in the guts of Bonnethead Sharks (Sphyrna tiburo) provide insight into their digestive strategy and evidence for microbial digestion in their hindguts. Comparative Biochemistry and Physiology A 189:76-83. doi: 10.1016/j.cbpa.2015.07.013

Karasov W.H. and J. Diamond. 1983. Adaptive regulation of sugar and amino acid transport by vertebrate intestine. American Journal of Physiology, 245:G443-G462. doi: 10.1152/ajpgi.1983.245.4.G443

Karasov W.H. 1992. Tests of the adaptive modulation hypothesis for dietary control of intestinal nutrient transport. American Journal of Physiology, 263, R496-R502. doi: 10.1152/ajpregu.1992.263.3.R496

Karasov W.H. and A. Douglas. 2013. Comparative digestive physiology. Comprehensive Physiology 3:741-783. doi: 10.1002/cphy.c110054 
Karasov W.H and I.D. Hume. 1997. Vertebrate gastrointestinal system. In: Dantzler W (Ed.) Handbook of Comparative Physiology (pp. 409-480). Bethesda, MD: American Physiological Society.

Karasov W.H. and C. Martínez del Rio. 2007. Physiological ecology: how animals process energy, nutrients, and toxins. Princeton, NJ USA: Princeton University Press.

Karasov W.H., D.H. Solberg, and J. Diamond. 1985. What transport adaptations enable mammals to absorb sugars and amino acids faster than reptiles? Am J Physiol 249: G271G283 doi:10.1152/ajpgi.1985.249.2.G271

King, G. 1996. Reptiles and herbivory. Chapman \& Hall, London, UK.

Kohl K.D., P. Brzek, and W. Karasov. 2011. Pancreatic and intestinal carbohydrases are matched to dietary starch level in wild passerine birds. Physiol Biochem Zool 84:195-203 doi: $10.1086 / 658146$

Kohl K.D., M. Samuni-Blank, P. Lymberakis, P. Kurnath, I. Izhaki, Z. Arad, W.H. Karasov, and M.D. Dearing. 2016a. Effects of fruit toxins on intestinal and microbial beta-glucosidase activities of seed-dispersing rodents (Acomys spp.). Physiol Biochem Zool 89:198-205 doi: $10.1086 / 685546$

Kohl K.D., A. Brun, M. Magallanes, J. Brinkerhoff, A. Laspiur, J.-C. Acosta, S.R. Bordenstein, and E. Caviedes-Vidal. 2016b. Physiological and microbial adjustments to diet quality permit facultative herbivory in an omnivorous lizard. J Exp Biol 219:1903-1912. doi: $10.1242 /$ jeb. 138370

Le H.T.M.D., X.T. Shao, Å. Krogdahl, T.M. Kortner, I. Lein, K. Kousoulaki, K.K. Lie, and Ø. Sæle. 2019. Intestinal function of the stomachless fish, ballan wrasse (Labrus bergylta). Front Mar Sci 6:140 doi:10.3389/fmars.2019.00140

Leigh S.C., B.-Q. Nguyen-Phuc, and D.P. German. 2018a. The effects of protein and fiber content on gut structure and function in zebrafish (Danio rerio). J Comp Physiol B 188:237-253 doi: 10.1007/s00360-017-1122-5

Leigh S.C., Y.P. Papastamatiou, and D.P. German. 2018b. Seagrass digestion by a notorious "carnivore". Proc Royal Soc B 285: 20181583. doi: 10.1098/rspb.2018.1583.

Lemieux-Labonté V., C. Vigliotti, S. Dowd, Z. Tadić, B.A. Wehrle, D.P. German, A. Herrel, F.J. Lapointe, P. Lopez, and E. Bapteste. (Unpubl data) Targeted changes in the gut microbiota in natural populations of lizards with different diets.

Lentle R.G. and P.W.M. Janssen. 2008. Physical characteristics of digesta and their influence on flow and mixing in the mammalian intestine: a review. J Comp Physiol B 178:673-690. doi: 10.1007/s00360-008-0264-x

Love R.J., R.G. Lentle, and P. Asvarujanon. 2013. An expanded finite element model of the intestinal mixing of digesta. Food Dig. 4:26-35. doi: 10.1007/s13228-012-0017-x

Liwanag H.E.M., D. Haro, B. Callejas, G. Labib, and G.B. Pauly. 2018. Thermal tolerance varies with age and sex for the nonnative Italian Wall Lizard (Podarcis siculus) in Southern California. J of Thermal Biol 78:263-269. doi: 10.1016/j.jtherbio.2018.10.010

Macfarlene S. and G.T. Macfarlene. 2003. Regulation of short-chain fatty acid production. The Proceedings of the Nutrition Society 62:67-72. doi: 10.1079/PNS2002207

Marsh R.S., C. Moe, R.B. Lomneth, J.D. Fawcett, and A. Place. 2001. Characterization of gastrointestinal chitinase in the lizard Sceloporus undulatus garmani (Reptilia: Phrynosomatidae). Comp Biochem Physiol B 128:675-682 doi: 10.1016/S10964959(00)00364-X 
Mathur R., G. Kim, W. Morales, J. Sung, E. Rooks, V. Pokkunuri, . . . and M. Pimentel. 2013. Intestinal Methanobrevibacter smithii but not total bacteria is related to diet-induced weight gain in rats. Obesit 21:748-754. doi:10.1002/oby.20277

McBee R.H. and V.H. McBee. 1982. The hindgut fermentation in the green iguana, Iguana iguana. In: Burghardt GM, Rand AS (Eds.), Iguanas of the world: Their behavior, ecology, and conservation (pp. 77-83). Park Ridge, New Jersey: Noyes Publications.

McConnachie S. and G.J. Alexander. 2004. The effect of temperature on digestive and assimilation efficiency, gut passage time and appetite in an ambush foraging lizard, Cordylus melanotus melanotus. J Comp Physiol B 174: 99-105. doi: 10.1007/s00360-0030393-1

McDowell E.M. and B.F. Trump. 1976. Histologic fixatives suitable for diagnostic light and electron microscopy. Arch Pathol Lab Med 100:405-414.

Mo J., T. Yang, X. Song, and J. Chang. 2004. Cellulase activity in five species of important termites in China. Appl Entomol Zool 39:635-636. doi: 10.1303/aez.2004.635

Moran N.A., H. Ochman, and T.J Hammer. 2019. Evolutionary and ecological consequences of gut microbial communities. Ann Rev Ecol Evol System 50: 20.1-20.25

Nakashima A., H. Watanabe, H. Saitoh, G. Tokuda, and J.I. Azuma. 2002. Dual cellulosedigesting system of the wood-feeding termite, Coptotermes formosanus Shiraki. Insect Biochem Mol Biol 32:777-784. doi: 10.1016/s0965-1748(01)00160-6

Naya D.E., C. Veloso, P. Sabat, and F. Bozinovic. 2009. Seasonal flexibility of organ mass and intestinal function for the Andean lizard Liolaemus nigroviridis. JEB 311:270-277. doi: $10.1002 / \mathrm{jez} .525$

Nevo E., G. Gorman, M. Soule, S.Y. Yang, R. Clover, and V. Jovanovic. 1972. Competitive exclusion between insular Lacerta species (Sauria, Lacertidae). Oecologia 10:183-190 doi: 10.1007/BF00347990

Pafilis P., J. Foufopoilos, P. Lymberakis, and E. Valakos. 2007. Digestive performance in five Mediterranean lizard species: effects of temperature and insularity. J Comp Physiol B 177:49-60 doi: 10.1007/s00360-006-0108-5

Penry D.L. and P.A. Jumars. 1986. Chemical reactor analysis and optimal digestion. BioScience 36:310-315 doi: 10.2307/1310235

Penry D.L. and P.A. Jumars. 1987. Modeling animal guts as chemical reactors. Am Nat 129:6996. doi: $10.1086 / 284623$

Perry G.H., N.J. Dominy, K.G. Claw, A.S. Lee, H. Fiegler, R. Redon, J. Werner, et al. 2007. Diet and the evolution of human amylase gene copy number variation. Nat Genet 39:12561260. doi: $10.1038 / \mathrm{ng} 2123$

Piersma T. and J. Drent. 2003. Phenotypic flexibility and the evolution of organismal design. Trends in Ecology and Evolution 18:228-233. doi: 10.1016/S0169-5347(03)00036-3

Podnar M., W. Mayer, and N. Tvrtković. 2005. Phylogeography of the Italian Wall Lizard, Podarcis sicula, as revealed by mitochondrial DNA sequences. Molec Ecol 14:575-588 doi:10.1111/j.1365-294X.2005.02427.x

Potts R.C. and P.H. Hewitt. 1973. The distribution of intestinal bacteria and cellulase activity in the harvester termite Trinervitermes trinervoides (Nasutitermitinae). Insect Soc 20:215220. doi: 10.1007/BF02223191

Pough F.H. 1973. Lizard energetics and diet. Ecology 54:837-844. doi: 10.2307/1935678

Pritchard G.T. and C.T. Robbins. 1990. Digestive and metabolic efficiencies of grizzly and black bears. Can. J. Zool. 68: 1645-1651 
986

987

988

989

990

991

992

993

994

995

996

997

998

999

1000

1001

1002

1003

1004

1005

1006

1007

1008

1009

1010

1011

1012

1013

1014

1015

1016

1017

1018

1019

1020

1021

1022

1023

1024

1025

1026

1027

1028

1029

Pryor G.S. and K.A. Bjorndal. 2005. Effects of the nematode Gyrinicola batrachiensis on development, gut morphology, and fermentation in bullfrog tadpoles (Rana catesbeiana): a novel mutualism. J Exp Zool 303:704-382. doi: 10.1002/jez.a.192

Pyke G.H., H.R. Pulliam, and E.L. Charnov. 1977. Optimal foraging: A selective review of theory and tests. The Quarterly Review of Biology 52(2):137-154. doi: 10.1086/409852

Sagonas K., P. Pafilis, and E.D. Valakos. 2015. Effects of insularity on digestion: living on islands induces shifts in physiological and morphological traits in island reptiles. Sci of Nat 102:1-7. doi: 10.1007/s00114-015-1301-8

Samuel B.S. and J.I. Gordon. 2006. A humanized gnotobiotic mouse model of host-archaealbacterial mutualism. Proceedings of the National Academy of Sciences 103:10011-10016. doi:10.1073/pnas.0602187103

Schondube J.E., L.G. Herrera-M., and C. Martínez del Rio. 2001. Diet and the evolution of digestion and renal function in phyllostomid bats. Zoology 104:59-73. doi: 10.1078/09442006-00007

Sibly R.M. 1981. Strategies of digestion and defecation. In: Townsend CR, Calow PA (Eds.), Physiological ecology: An evolutionary approach to resource use (pp. 109-139). Sunderland, Massachusetts: Sinauer Associates

Skea G., D. Mountfort, and K.D. Clements. 2005. Gut carbohydrases from the New Zealand marine herbivorous fishes Kyphosus sydneyanus (Kyphosidae), Aplodactylus arctidens (Aplodactylidae), and Odax pullus (Labridae). Comp Biochem Physiol B 140:259-269. doi: 10.1016/j.cbpc.2004.10.008

Skoczylas R. 1978. Physiology of the digestive tract. In: Gans CG, Gans KA (Eds.), Biology of the reptilia, Volume 8 (pp. 589-717). New York, New York: Academic Press

Spiller D.A., J. Piovia-Scott, A.N. Wright, L.H. Yang, G. Takimoto, T.W. Schoner, and T. Iwata. 2010. Marine subsidies have multiple effects on coastal food webs. Ecology 91:1424-1434 doi: 10.1890/09-0715.1

Stevens C.E. and I.D. Hume. 2004. Comparative physiology of the vertebrate digestive system. Cambridge, United Kingdom: Cambridge University Press.

Stevens C.E. and I.D. Hume. 1998. Contributions of microbes in vertebrate gastrointestinal tract to production and conservation of nutrients. Physiol Rev 78:393-427. doi: 10.1152/physrev.1998.78.2.393

Van Damme R. 1999. Evolution of herbivory in lacertid lizards: effects of insularity and body size. J Herpetol 33:663-674 doi: 10.2307/1565584

van der Wielen N., P.J. Moughan, and M. Mensink. 2017. Amino acid absorption in the large intestine of humans and porcine models. J Nutr 147: 1493-1498 doi:10.3945/jn.117.248187

Vervust B., P. Pafilis, E.D. Valakos, and R. Van Damme. 2010. Anatomical and physiological changes associated with a recent dietary shift in the lizard Podarcis sicula. Physiol Biochem Zool 83:632-642 doi: 10.1086/651704

Vidal M.A. and P. Sabat. 2010. Stable isotopes document mainland-island divergence in resource use without concomitant physiological changes in the lizard Liolaemus pictus Comp Biochem Physiol B 156:61-67 doi: 10.1016/j.cbpb.2010.02.005

Vonk H.J. and J.R.H. Western. 1984. Comparative biochemistry and physiology of enzymatic digestion. Orlando, Florida: Academic Press 
Wagner C.E., P.B. McIntyre, K.S. Buels, D.M, Gilbert, and E. Michel. 2009. Diet predicts intestine length in Lake Tanganyika's cichlid fishes. Functional Ecology 23:1122-1131. doi: 10.1111/j.1365-2435.2009.01589.x

Wehrle B.A. 2018. Who, when, and how much? The context dependency of rapid evolution in response to a dietary shift. Dissertation, University of California Irvine. Proquest ID: 15399.

Wilson K.J. and A.K. Lee. 1974. Energy expenditure of a large herbivorous lizard. Copeia 1974:338-348. doi: 10.2307/144252

\section{Figure Captions}

Figure 1: Podarcis siculus island collection sites showing Pod Kopište (source population) and Pod Mrčaru (newly omnivorous population). The box in the bottom map shows the area of the inset. Zagreb (mainland population) not pictured.

Figure 2: Potential patterns of digestive enzyme activities across intestinal regions and representative examples of lizard guts from each population (with stomachs). Pancreatic digestive enzymes are secreted into the proximal intestine and are expected to decrease along the gut. Brush border enzymes are produced at the brush border of the epithelial cells and the intestinal lumen, generally peaking in activity in the mid intestine. High enzyme activities in the proximal or mid intestines and/or their contents would be due to the lizards themselves increasing those enzyme activities. Microbial enzymes produced by the microbiome tend to peak in the hindgut where symbiotic microbes are housed. Increased enzyme activities in the hindgut contents are likely produced by microbial symbionts. Modified from German et al. 2015. For enzymatic analyses, we removed the esophagus and stomach from the intestines at the pyloric sphincter. The hindgut was easily identified as its diameter is enlarged compared to the proximal and mid intestine. We defined the proximal and mid intestines as half of each portion of the remaining tissue length.

Figure 3: (a) Regional and (b) total intestinal mass (without contents) in Pod Kopište (source), Pod Mrčaru (new omnivore), and Zagreb (mainland) populations. Gut regions are proximal intestine (PI), mid intestine (MI) and hindgut (H) and presented as a percentage of body mass. Values are mean \pm standard deviation. $n=7$ in all except $n=6$ in Pod Mrčaru PI. Comparisons of populations were done via ANCOVA with body mass as a covariate. No particular region showed differences in mass (a), but the Zagreb population had lower total intestinal masses than the Pod Mrčaru population (b) that were also significantly affected by body mass. Pod Kopište intestinal masses were not different from either population.

Figure 4: Epithelial Surface Magnification (ESM), the ratio of inner perimeter length of mucosa to inner perimeter length of serosa in proximal intestine (PI), mid intestine (MI), proximal half of hindgut $(\mathrm{H})$, distal half of hindgut $(\mathrm{H}+)$. Values are mean \pm standard deviation, $n=3$. Comparisons of populations were done via equal variance t-test. We found no differences by population. Cross section images are representative stained histological sections from each gut region of Pod Kopište (source) and Pod Mrčaru (new omnivore) populations. Not to scale: each perpendicular black scale bar represents $500 \mu \mathrm{m}$ for the two images it lies between. 
Figure 5: (a) amylase activity in $\mu$ mol glucose liberated $\mathrm{g}^{-1} \mathrm{~min}^{-1}$, " $\mathbf{X}$ " denotes undetectable activity. (b) $\beta$-glucosidase and (c) $\mathrm{N}$-acetyl- $\beta$-D-glucosaminidase (NAG) activities in nmol MUB liberated $\mathrm{g}^{-1} \mathrm{~min}^{-1}$, (d) trehalase activity in $\mu$ mol glucose liberated $\mathrm{g}^{-1} \mathrm{~min}^{-1}$, (e) trypsin in nmol and (f) aminopeptidase activities $\mu \mathrm{mol}$ of $\mathrm{p}$-nitroaniline liberated $\mathrm{g}^{-1} \mathrm{~min}^{-1}$ throughout the gut in Pod Kopište (source), Pod Mrčaru (omnivore), and Zagreb (mainland) populations. Values are mean \pm standard deviation, Pod Kopište $n=4-7$, Pod Mrčaru $n=3-7$, Zagreb $n=3-6$. In (b) populations by tissue and tissues within populations were compared via separate ANOVAs, shared letters above icons denote no differences. In (a, c-f) comparisons of populations were done via ANOVA where lines of a different elevation for a gut region indicate significant differences for that population and overlapping lines indicate no differences.

Figure 6: Total $\beta$-glucosidase activity (a) in nmol MUB liberated min and total aminopeptidase activity (b) in $\mu$ mol p-nitroaniline liberated $\min ^{-1}$. Values are mean \pm standard deviation, $n=7$, Zagreb $n=6$. Populations compared via ANOVAs, different letters above icons denote significant differences.

Figure 7: Trypsin activity in the pancreas in nmol p-nitroaniline liberated $\mathrm{g}^{-1} \mathrm{~min}^{-1}$ in Pod Kopište (source), Pod Mrčaru (new omnivore), and Zagreb (mainland) populations. Values are mean \pm standard deviation, $n=10$, Zagreb $n=6$. Populations compared via ANOVA, different letters above icons denote significant differences.

Figure 8: Organic matter digestibility on experimental diets in lizards from in Pod Kopište (blue, source) and Pod Mrčaru (green, new omnivore) presented as box and whisker plots representing each quartile $(n=5)$. Populations compared via ANOVA separately for each diet. $\uparrow$ denotes significant differences at $\mathrm{P}<0.05$ level. 
Table 1. Predictions of relative diet, gut morphology, enzyme activities, fermentation products, and digestibility in Pod Mrčaru (new omnivore), Pod Kopište (source), and Zagreb (mainland) populations and whether these hypotheses were supported by the results of this study. *Note that gut length refers to the combined length of the esophagus, stomach, and intestines

\begin{tabular}{|c|c|c|c|c|}
\hline Characteristics & Pod Mrčaru & Pod Kopište & Zagreb & Supported? \\
\hline Mass of stomach contents & highest & low & low & yes \\
\hline Diet: \% plant matter & highest & low & low & yes \\
\hline Gut Length* & long & short & short & no \\
\hline Intestinal mass & heaviest & light & light & no \\
\hline ESM & largest & least & least & no \\
\hline \multicolumn{5}{|l|}{ Enzyme activities (substrate) } \\
\hline \multicolumn{5}{|l|}{ pancreatic } \\
\hline$\alpha$-amylase $\quad\left(\right.$ starch $\left.^{\mathrm{a}}\right)$ & moderate & low & low & in $\mathrm{HC}$ only \\
\hline Trypsin (protein) & moderate/high & high & high & no \\
\hline Lipase (fats) & moderate & moderate & moderate & yes \\
\hline \multicolumn{5}{|l|}{ intestinal } \\
\hline N-acetyl- $\beta$-D-glucosaminidase & low & moderate & moderate & no \\
\hline Trehalase (arthropod sugars) & low & moderate & moderate & no \\
\hline Maltase (disaccharides ${ }^{\mathrm{a}}$ ) & moderate & low & low & no \\
\hline Aminopeptidase (dipeptides) & moderate/high & high & high & no \\
\hline \multicolumn{5}{|l|}{ microbial } \\
\hline$\beta$-glucosidase $\left(6\right.$-glucosides $\left.{ }^{\mathrm{b}}\right)$ & high & low & low & no \\
\hline \multicolumn{5}{|l|}{ SCFAs } \\
\hline acetate & high & low & low & no \\
\hline propionate & high & low & low & no \\
\hline butyrate & moderate & low & low & no \\
\hline isobutyrate & moderate & low & low & no \\
\hline valerate & low & moderate & moderate & no \\
\hline isovalerate & low & moderate & moderate & no \\
\hline \multicolumn{5}{|l|}{ Digestibility } \\
\hline plants & moderate & low & \multirow{3}{*}{$\begin{array}{c}\text { Not } \\
\text { measured }\end{array}$} & yes \\
\hline plants + insects & high & moderate & & yes \\
\hline insects & high & high & & yes \\
\hline
\end{tabular}

${ }^{\mathrm{a}}$ From plants, seeds, glycogen sources; ${ }^{\mathrm{b}}$ From plant cell wall sources. $\mathrm{HC}=$ hindgut contents. 
Table 2. Average stomach contents $( \pm \mathrm{SD})$ by mass of lizards from Pod Kopište, Pod Mrčaru, and Zagreb. We found empty stomachs in additional lizards (not included in the counts) from Pod Kopište $\left(n_{\text {empty }}=1\right)$ and Zagreb $\left(n_{\text {empty }}=3\right)$, but not Pod Mrčaru. Plant material is broken down into the percentages of each type, adding up to $100 \%$ of total plant material. "Other" consisted of rocks and feces.

\begin{tabular}{lccc} 
& Pod Kopište & Pod Mrčaru & Zagreb \\
\hline Mass of stomach contents & $94.50 \pm 68.0 \mathrm{mg}$ & $207.41 \pm 16.1 \mathrm{mg}$ & $98.79 \pm 123.2 \mathrm{mg}$ \\
& $n=30$ & $n=36$ & $n=4$ \\
(does not include individuals with empty stomachs) \\
\hline Plant material \% & $24.49 \pm 33.1$ & $64.24 \pm 30.8$ & $2.37 \pm 8.3$ \\
leaves & $6.25 \pm 25.0$ & $7.65 \pm 12.0$ & 0 \\
seeds & $81.25 \pm 40.3$ & $91.18 \pm 13.3$ & 0 \\
wood & $12.50 \pm 34.2$ & $1.18 \pm 3.0$ & 0 \\
fruit & 0 & 0 & 100 \\
\hline Animal material \% & $75.36 \pm 33.0$ & $35.58 \pm 30.9$ & $70.48 \pm 44.2$ \\
\hline Other \% & $0.15 \pm 0.8$ & $0.19 \pm 0.8$ & $25.37 \pm 22.8$ \\
\hline
\end{tabular}


Table 3. Total short-chain fatty acid (SCFA) concentrations and ratios of acetate: propionate: butyrate: isobutyrate: valerate: isovalerate to total SCFAs in hindguts of Pod Kopište (source; $n=4$ ), Pod Mrčaru (omnivore; $n=3$ ), and Zagreb (mainland outgroup, $n=1$ ) populations. Values are mean \pm standard deviation. Compared between populations using equal variance t-tests, * denotes significant differences between populations.

\begin{tabular}{lcl}
\hline Population & Total SCFA & Ratio \\
\hline Pod Kopište & $61.86 \pm 3.95 \mathrm{mM}$ & \\
\hline Pod Mrčaru & $19.22 \pm 8.63 \mathrm{mM} *$ & $56^{*}: 19: 16: 16: 5^{*}: 1: 1^{*}: 4^{*}$ \\
\hline Zagreb & $0.60 \mathrm{mM}$ & $65: 16: 11: 6: 0: 3$ \\
\hline
\end{tabular}


Table 4. Comparison of digestive enzyme activities ranges between the Podarcis siculus of the current study and previous work on lizard digestive physiology. Values have been converted so that units are directly comparable, however differing methodology may confound these comparisons. Bolded species and values are similar to those we measured in P. siculus. ${ }^{\text {an}} \mathrm{N}-$ acetyl- $\beta$-D-glucosaminidase

\begin{tabular}{|c|c|c|c|}
\hline Enzyme & Podarcis siculus: This Study & \multicolumn{2}{|c|}{ Previous Studies } \\
\hline $\begin{array}{l}\text { Amylase } \\
\text { (pancreas) }\end{array}$ & $80-137 \mu \mathrm{mol} \mathrm{min} \mathrm{m}^{-1} \mathrm{~g}^{-1}$ tissue & $\begin{array}{l}\text { Tupinambis meriange } \\
\text { Parry et al. } 2009\end{array}$ & $\begin{array}{l}5.82-12.7 \times 10^{5} \mu \mathrm{mol} \mathrm{min}^{-1} \\
\mathrm{~g}^{-1} \text { protein }\end{array}$ \\
\hline \multirow[t]{5}{*}{ Aminopeptidase } & Total: $0.22-0.81 \mu \mathrm{mol} \mathrm{min}{ }^{-1}$ & $\begin{array}{l}\text { Liolaemus pictus } \\
\text { Vidal and Sabat } 2010\end{array}$ & $0.11-0.21 \mu \mathrm{mol} \mathrm{min}-1$ \\
\hline & & $\begin{array}{l}\text { Lophognathis temporalis } \\
\text { Iglesias et al. } 2009\end{array}$ & $10.22-25.35 \mu \mathrm{mol} \mathrm{min}{ }^{-1}$ \\
\hline & $\begin{array}{l}\text { Total/g tissue: } 0.96-3.65 \mu \mathrm{mol} \\
\mathrm{min}^{-1} \mathrm{~g}^{-1}\end{array}$ & $\begin{array}{l}\text { Liolaemus nigriviridis } \\
\text { Naya et al. } 2009\end{array}$ & 2-4 $\mu \mathrm{mol} \mathrm{min} \mathrm{mg}^{-1} \mathrm{~g}^{-1}$ \\
\hline & & $\begin{array}{l}\text { Liolaemus ruibali } \\
\text { Kohl et al. } 2016 a\end{array}$ & $2.13 \pm 0.3 \mu \mathrm{mol} \mathrm{min} \mathrm{m}^{-1} \mathrm{~g}^{-1}$ \\
\hline & & $\begin{array}{l}\text { Heloderma suspectum } \\
\text { Christel et al. } 2007\end{array}$ & $9-21 \mu \mathrm{mol} \mathrm{min}^{-1} \mathrm{~g}^{-1}$ \\
\hline \multirow[t]{2}{*}{ Trehalase } & Total: $0.004-0.28 \mu \mathrm{mol} \mathrm{min}{ }^{-1}$ & $\begin{array}{l}\text { Liolaemus pictus } \\
\text { Vidal and Sabat } 2010\end{array}$ & 5.9-9.4 $\mu \mathrm{mol} \mathrm{min} \mathrm{m}^{-1}$ \\
\hline & $\begin{array}{l}\text { Total/g tissue: } 0.023-1.38 \mu \mathrm{mol} \\
\mathrm{min}^{-1} \mathrm{~g}^{-1}\end{array}$ & $\begin{array}{l}\text { Liolaemus nigriviridis } \\
\text { Naya et al. } 2009\end{array}$ & $\sim 2-6 \mu \mathrm{mol} \mathrm{min}{ }^{-1} \mathrm{~g}^{-1}$ \\
\hline \multirow[t]{4}{*}{ Maltase } & Total: $0.06-0.18 \mu \mathrm{mol} \mathrm{min}{ }^{-1}$ & $\begin{array}{l}\text { Liolaemus pictus } \\
\text { Vidal and Sabat } 2010\end{array}$ & $5.92-11.31 \mu \mathrm{mol} \mathrm{min}^{-1}$ \\
\hline & & $\begin{array}{l}\text { Lophognathis temporalis } \\
\text { Iglesias et al. } 2009\end{array}$ & 2.39-3.89 $\mu \mathrm{mol} \mathrm{min}-1$ \\
\hline & $\begin{array}{l}\text { Total/g tissue: } 0.273-0.782 \mu \mathrm{mol} \\
\mathrm{min}^{-1} \mathrm{~g}^{-1}\end{array}$ & $\begin{array}{l}\text { Liolaemus ruibali } \\
\text { Kohl et al. 2016a }\end{array}$ & $34.55 \pm 2.68 \mu \mathrm{mol} \mathrm{min}^{-1} \mathrm{~g}^{-1}$ \\
\hline & $\mathrm{Pl} / \mathrm{MI}: 0.458-0.872 \mu \mathrm{mol} \mathrm{min} \mathrm{m}^{-1} \mathrm{~g}^{-1}$ & $\begin{array}{l}\text { Liolaemus nigriviridis } \\
\text { Naya et al. } 2009\end{array}$ & $20-60 \mu \mathrm{mol} \mathrm{min} \mathrm{m}^{-1} \mathrm{~g}^{-1}$ \\
\hline \multirow[t]{5}{*}{$N^{\prime} G^{a}$} & Total: $2.16-4.311 \mathrm{nmol} \mathrm{min}^{-1}$ & $\begin{array}{l}\text { Lacerta viridis } \\
\text { Jeuniaux } 1961\end{array}$ & $1.2 \times 10^{7} \mathrm{nmol} \mathrm{min}-1$ \\
\hline & & $\begin{array}{l}\text { Uromastyx acanthinurus } \\
\text { Jeuniaux } 1963\end{array}$ & no detectible activity \\
\hline & & $\begin{array}{l}\text { Anolis carolinensis } \\
\text { Jeuniaux } 1963\end{array}$ & no detectible activity \\
\hline & & $\begin{array}{l}\text { Chamaeleo chamaelon } \\
\text { Jeuniaux } 1963\end{array}$ & $2.7 \times 10^{6} \mathrm{nmol} \mathrm{min}{ }^{-1}$ \\
\hline & $\begin{array}{l}\text { Total/g tissue: } 9.6-17.9 \mathrm{nmol} \\
\mathrm{min}^{-1} \mathrm{~g}^{-1}\end{array}$ & $\begin{array}{l}\text { Sceloporus undulatus } \\
\text { Marsh et al. } 2001\end{array}$ & $1.4 \times 10^{6} \mathrm{nmol} \mathrm{min}^{-1} \mathrm{~g}^{-1}$ \\
\hline
\end{tabular}




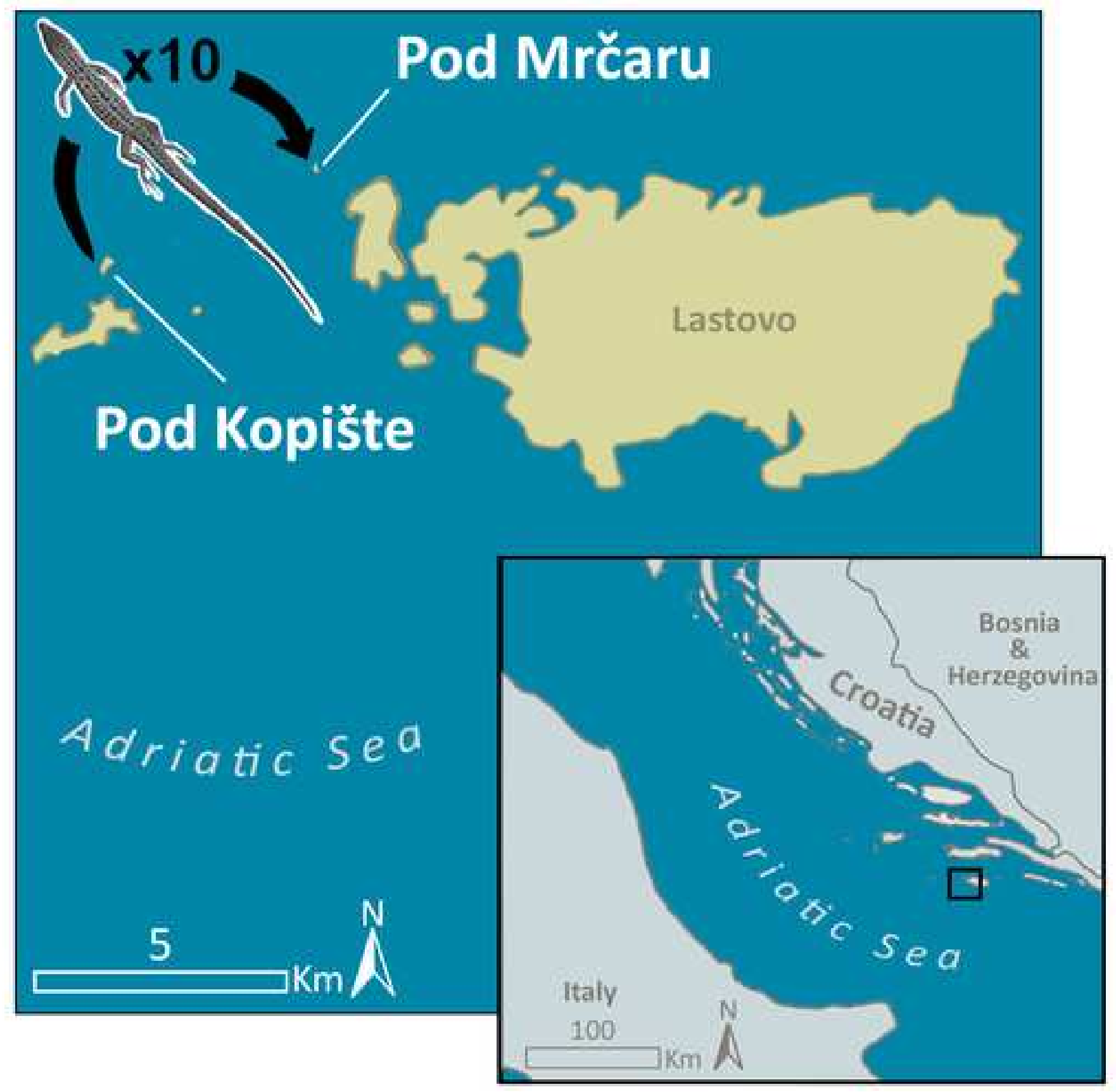



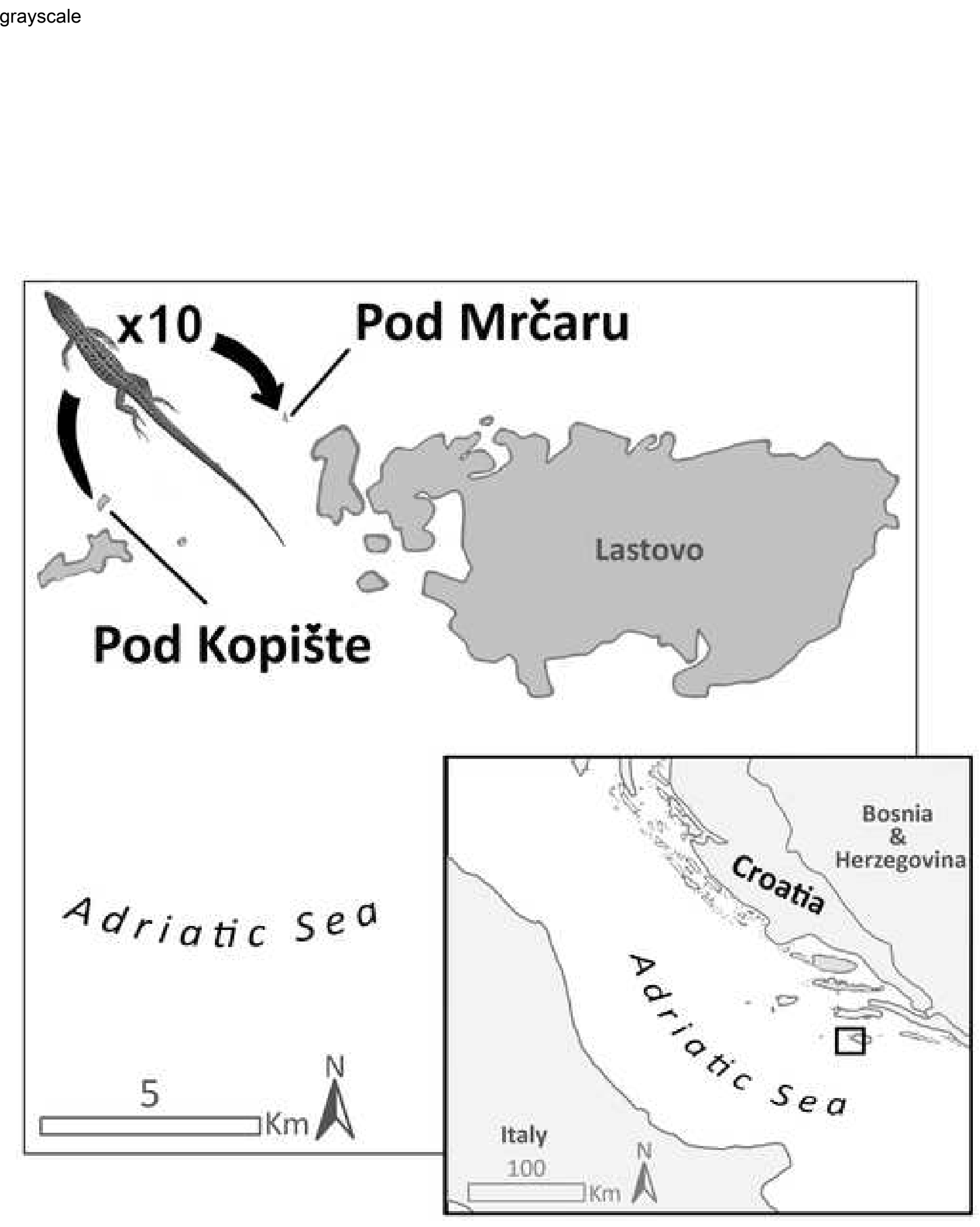

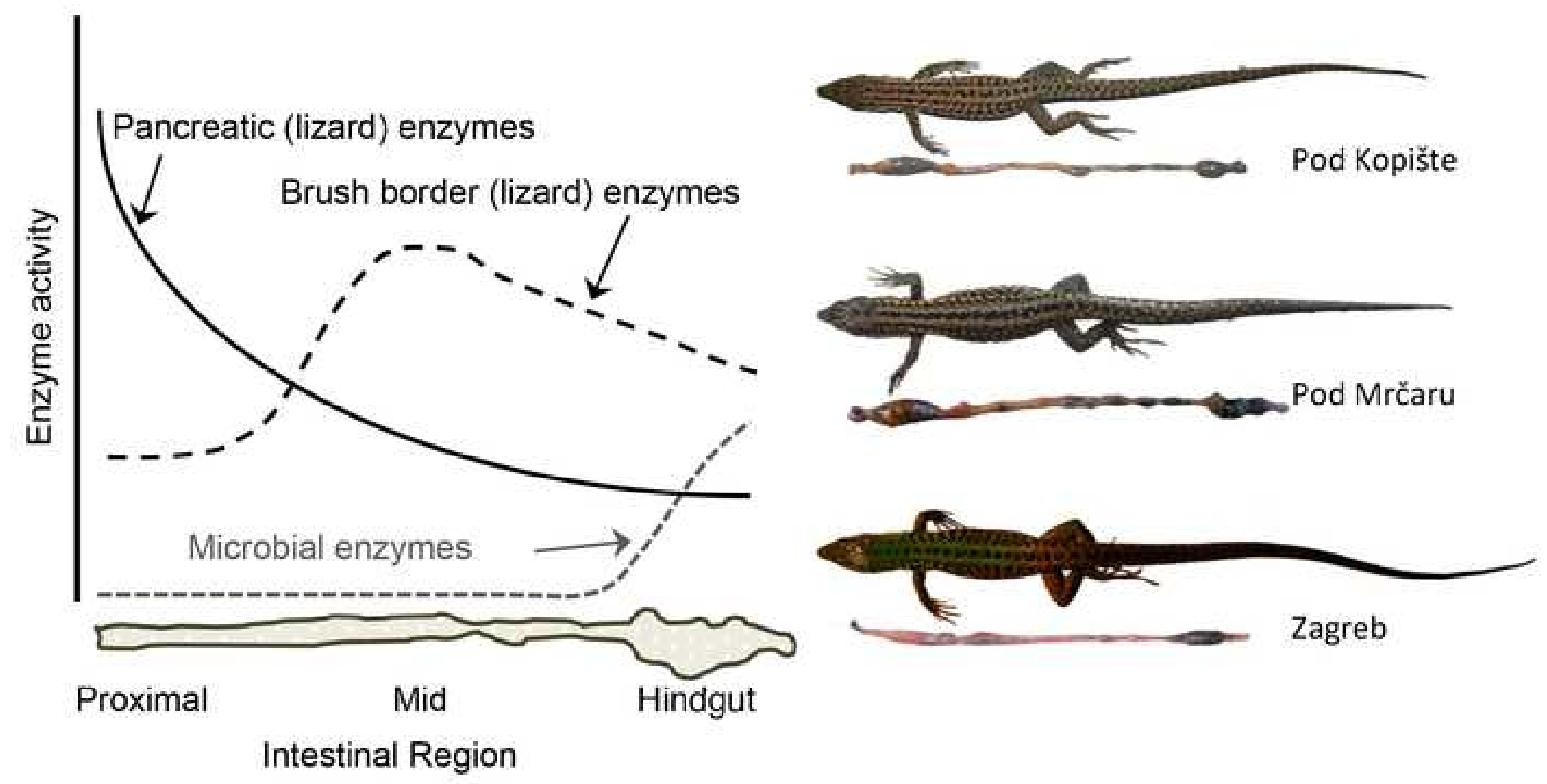

ntestinal Region

Zagreb 

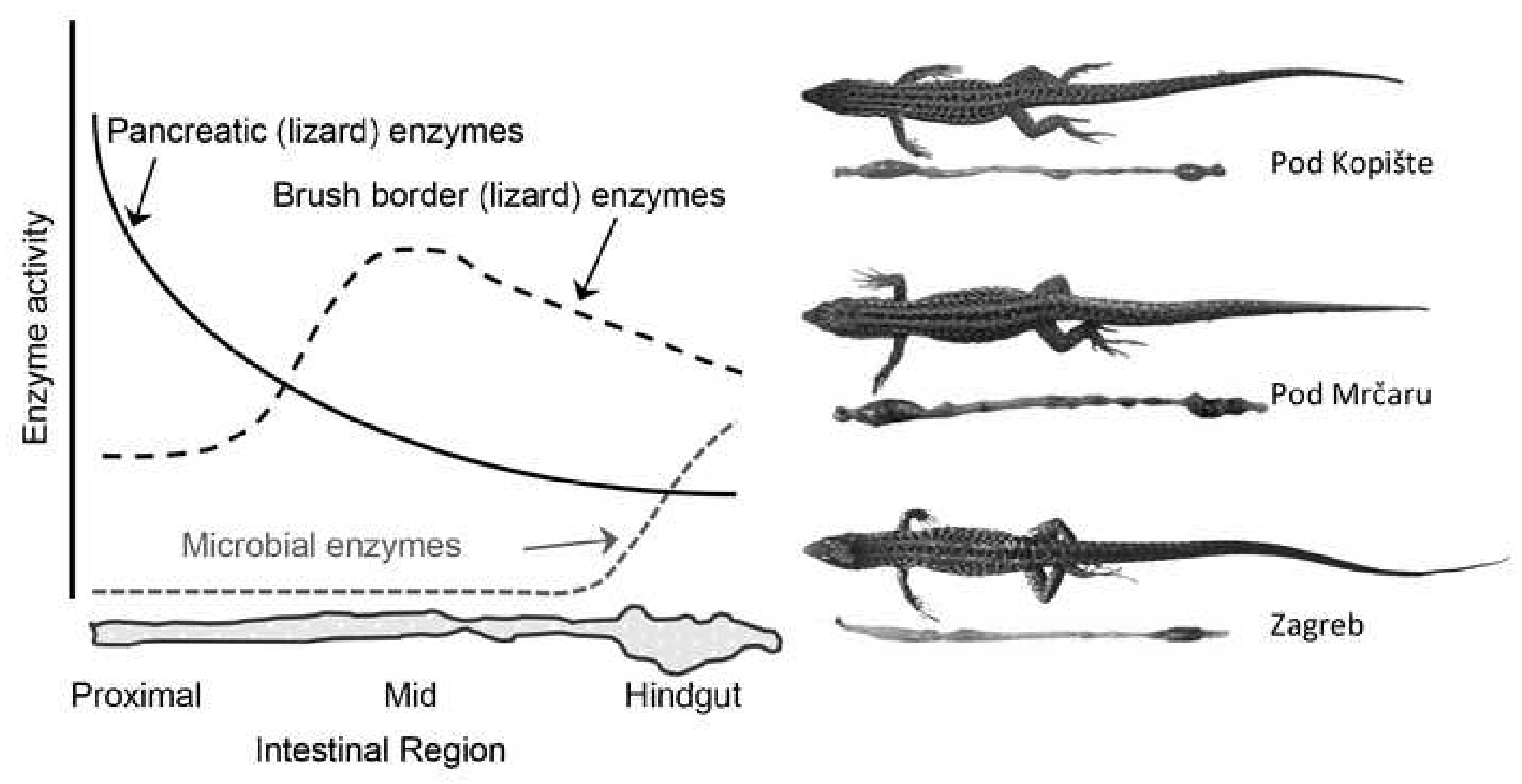

Intestinal Region

Zagreb 

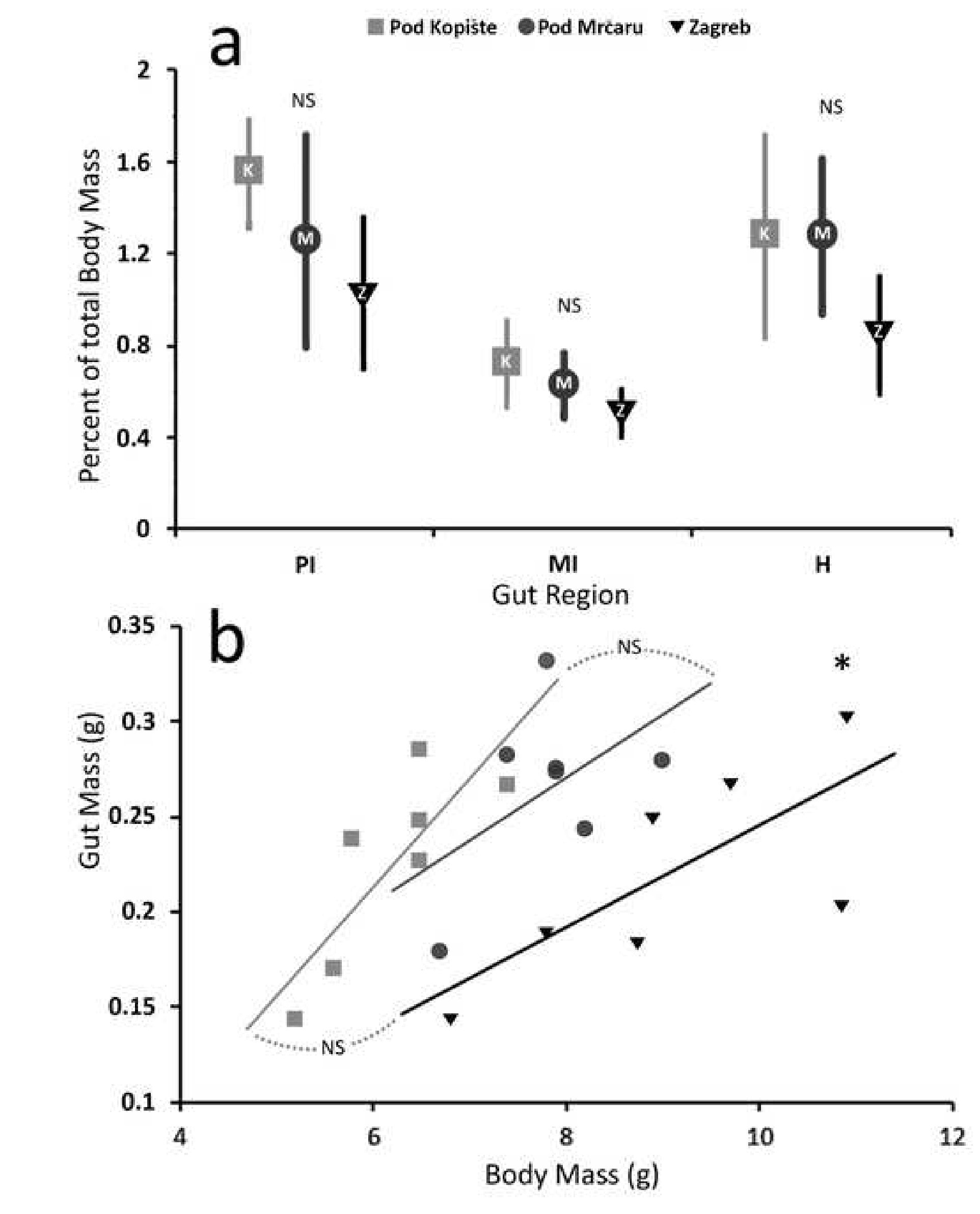

Figure 3 grayscale

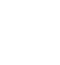

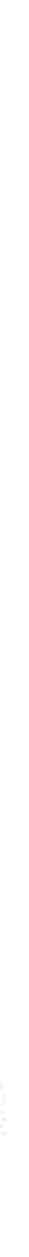




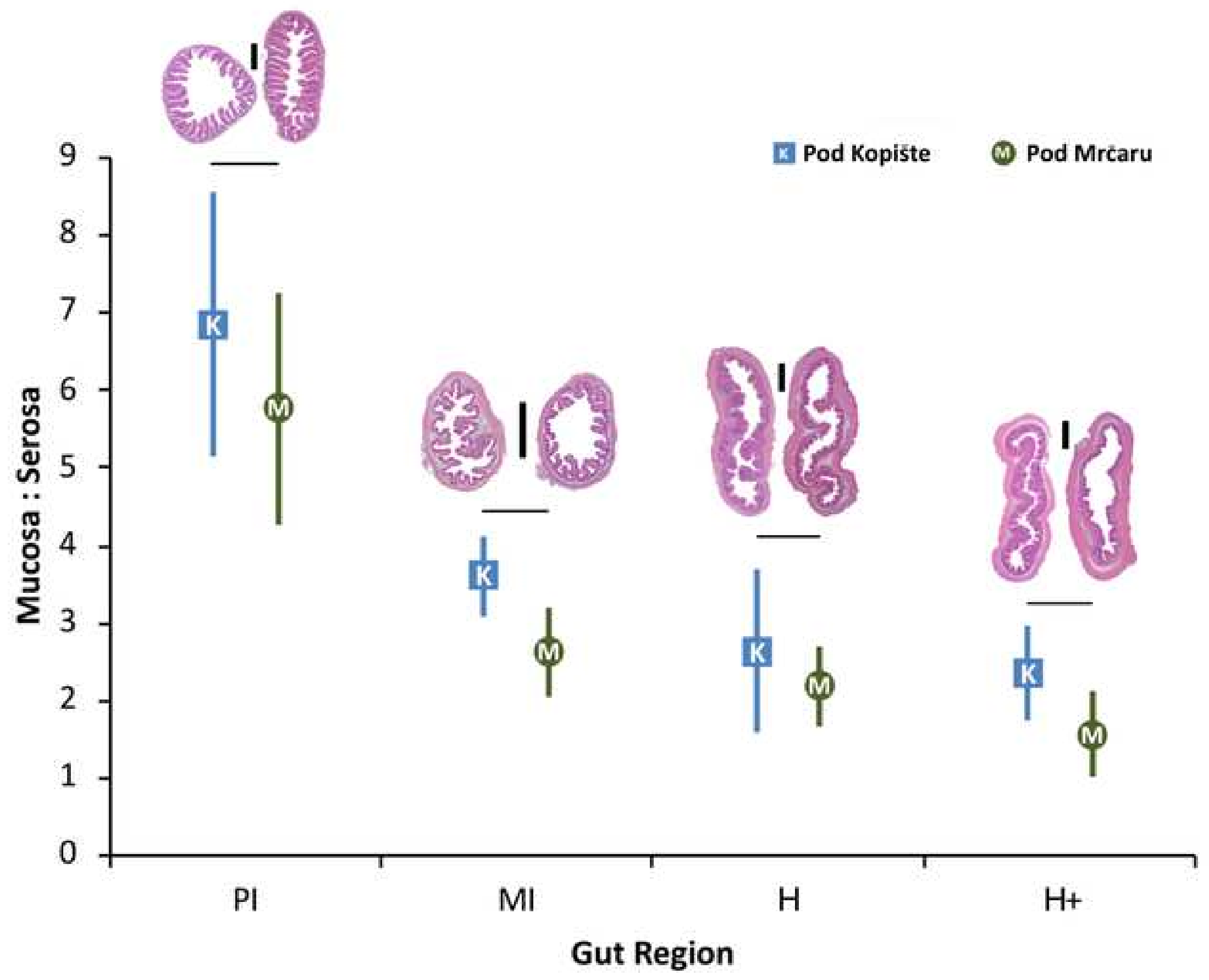




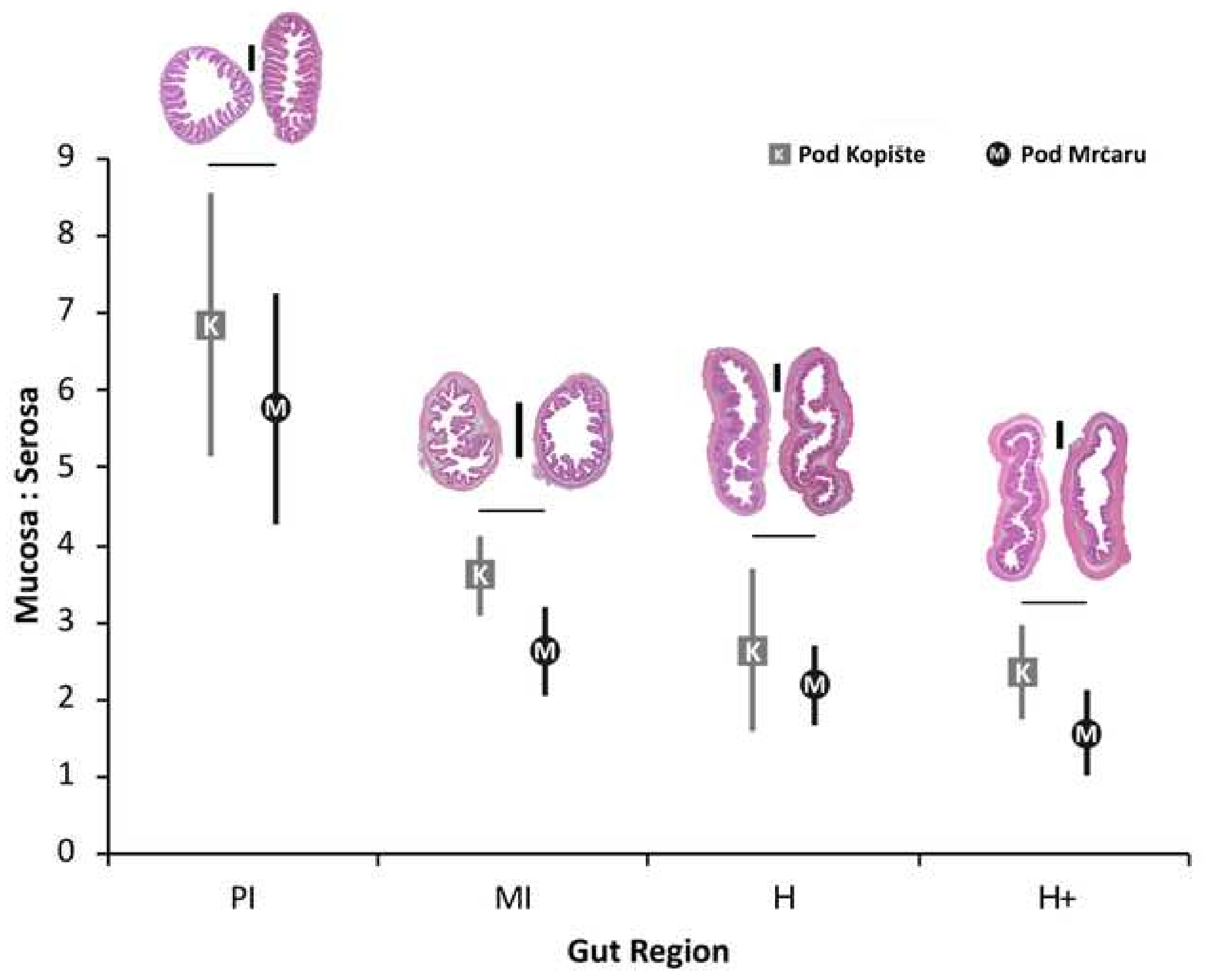



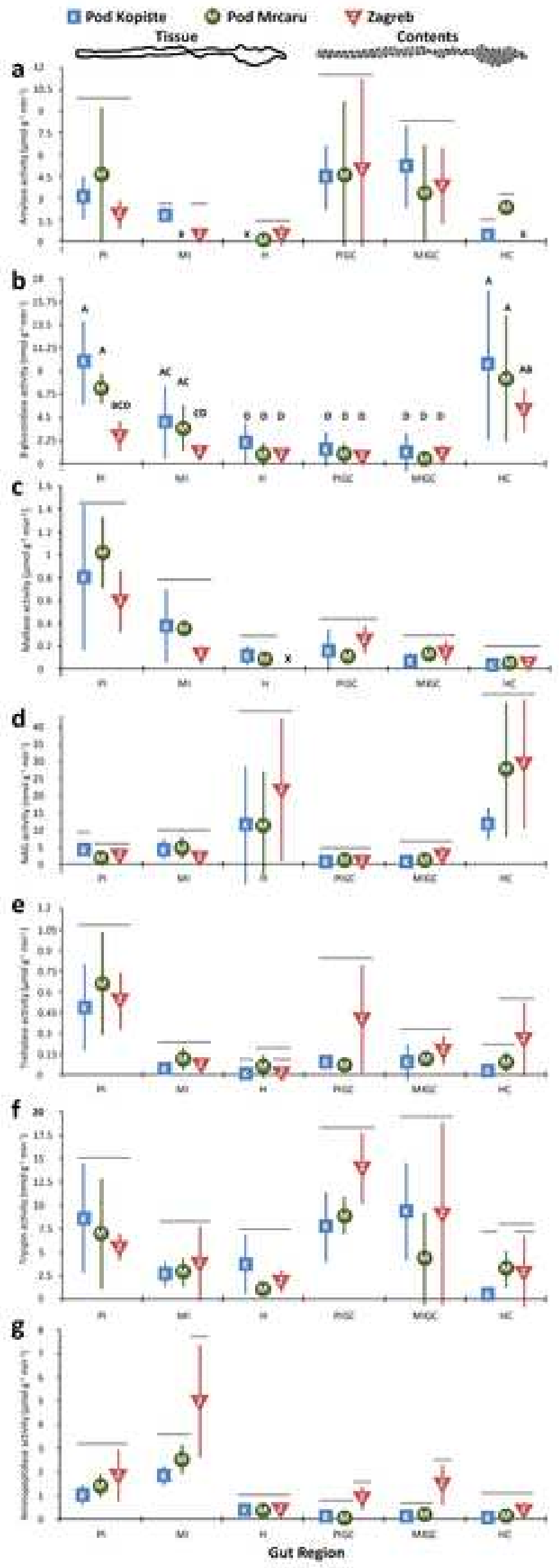

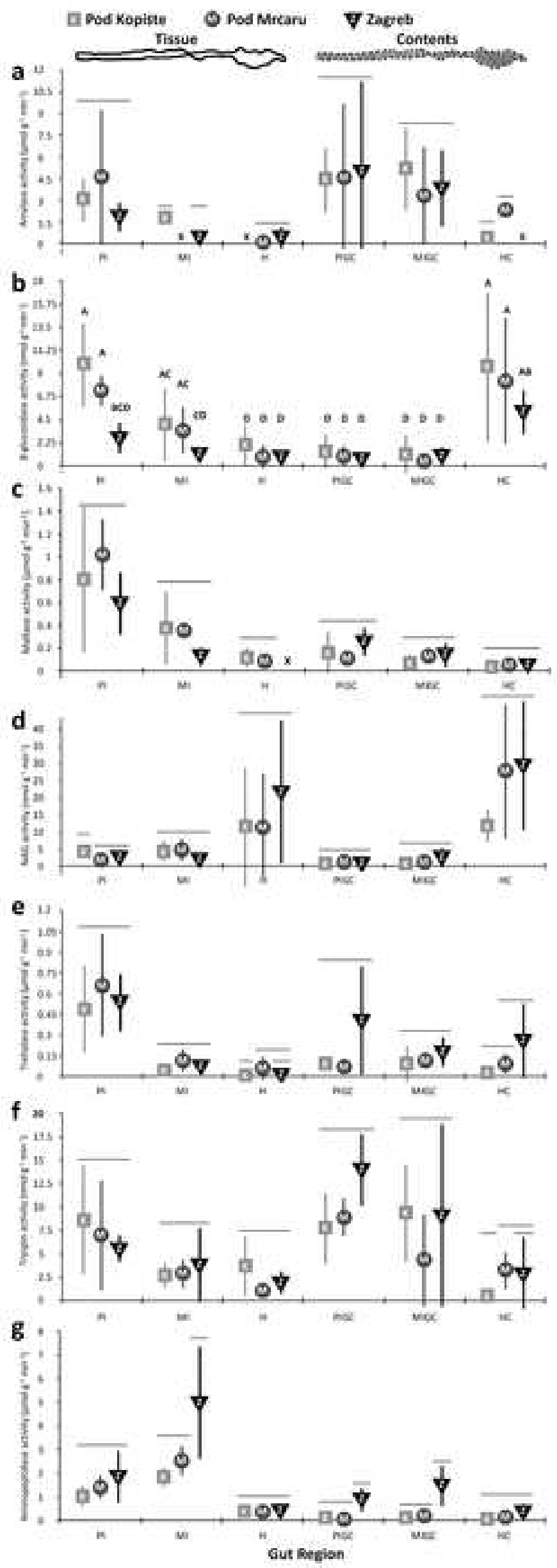

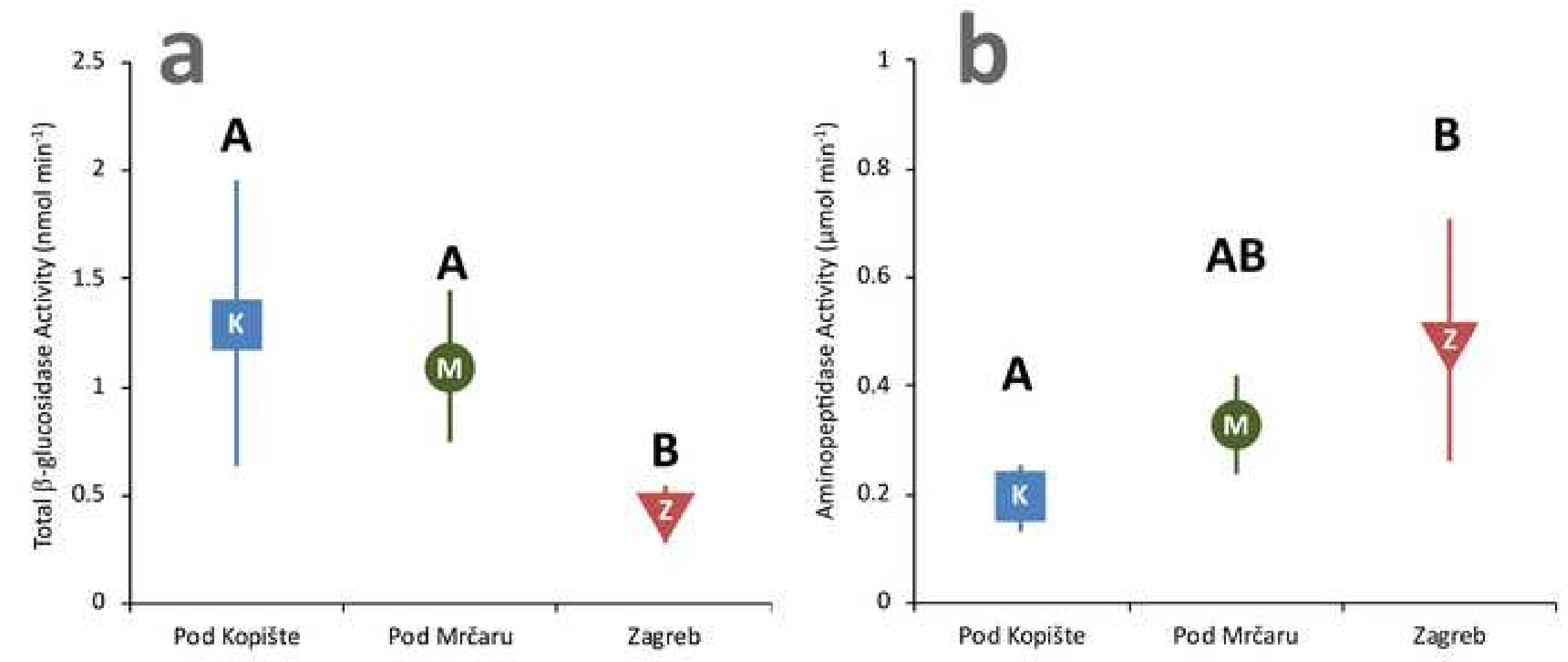

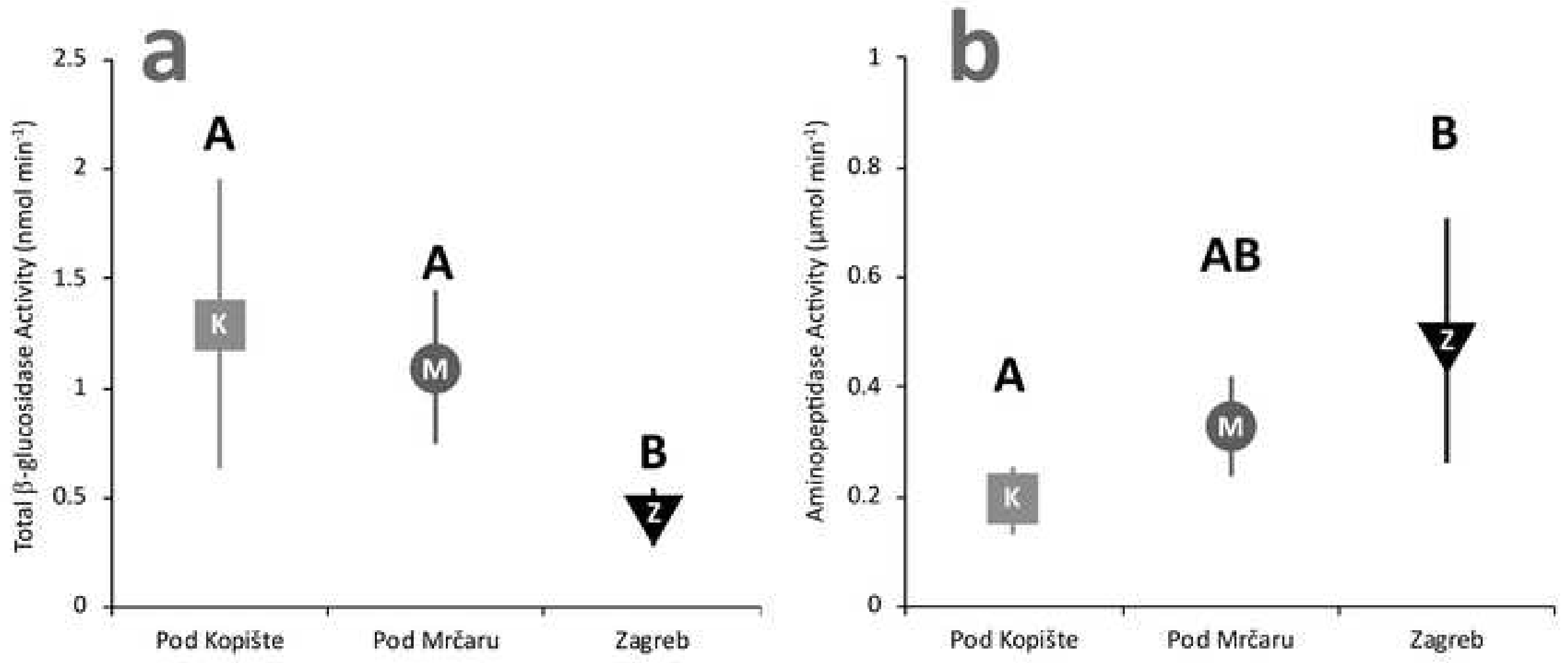


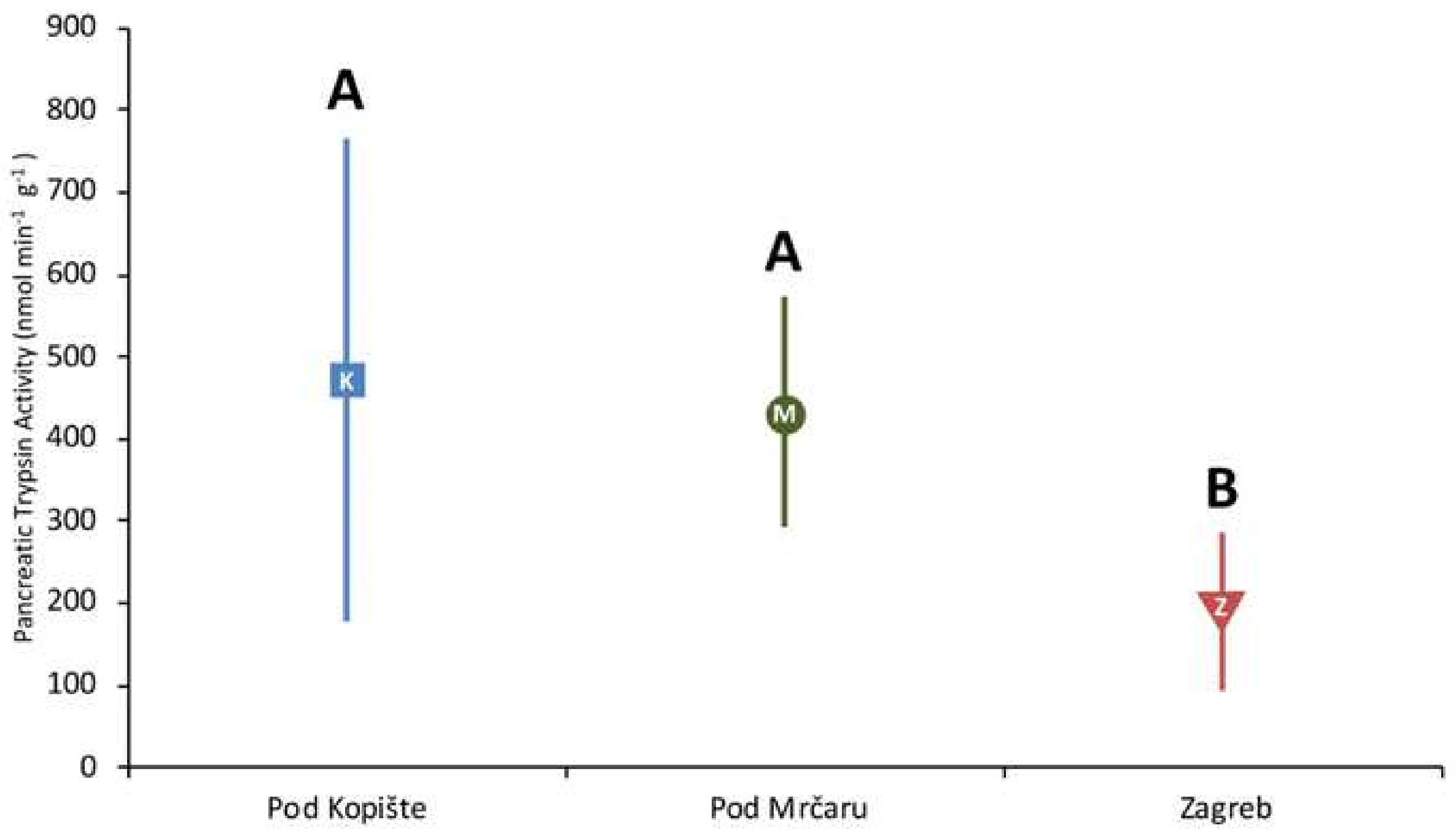




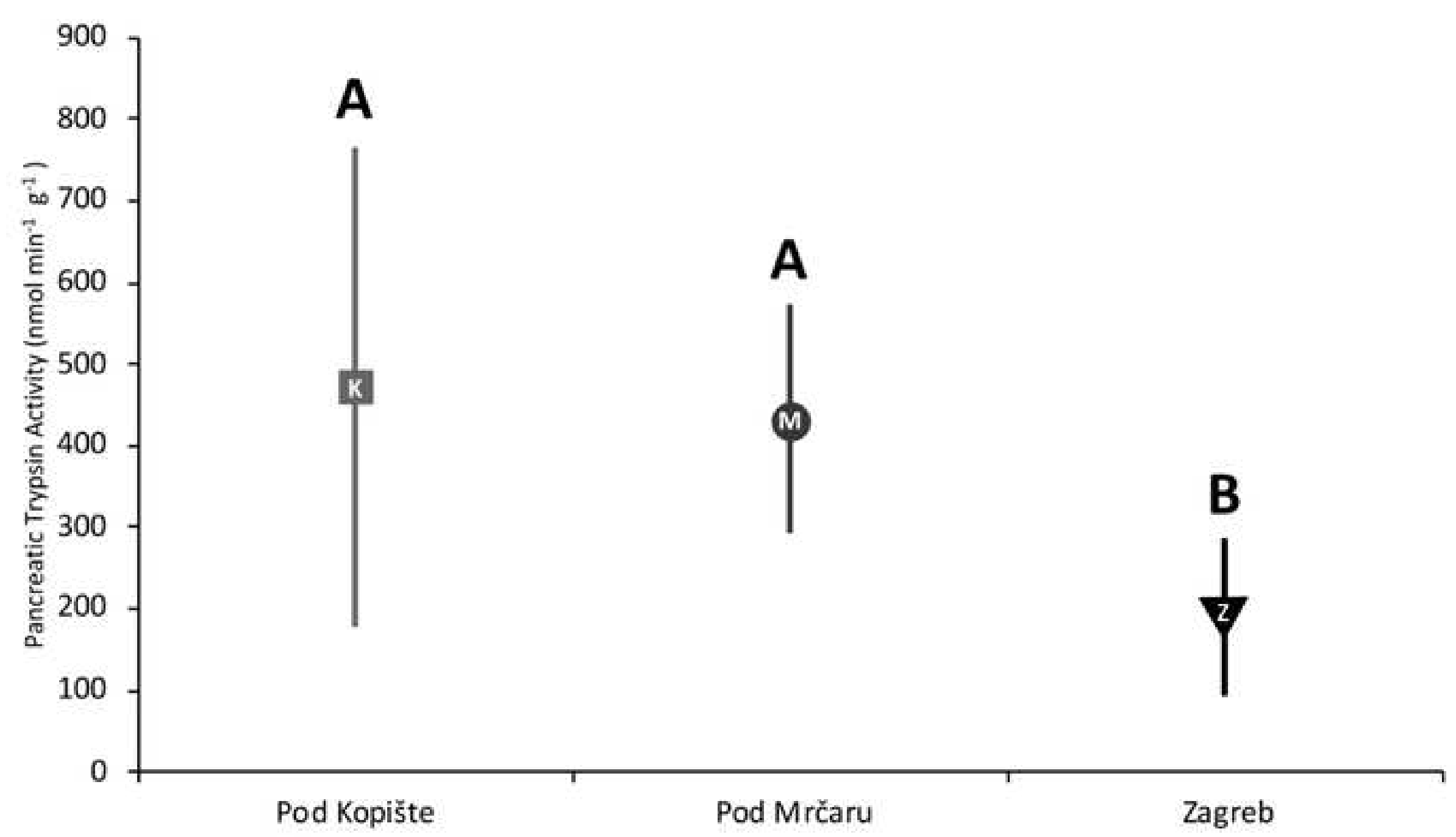




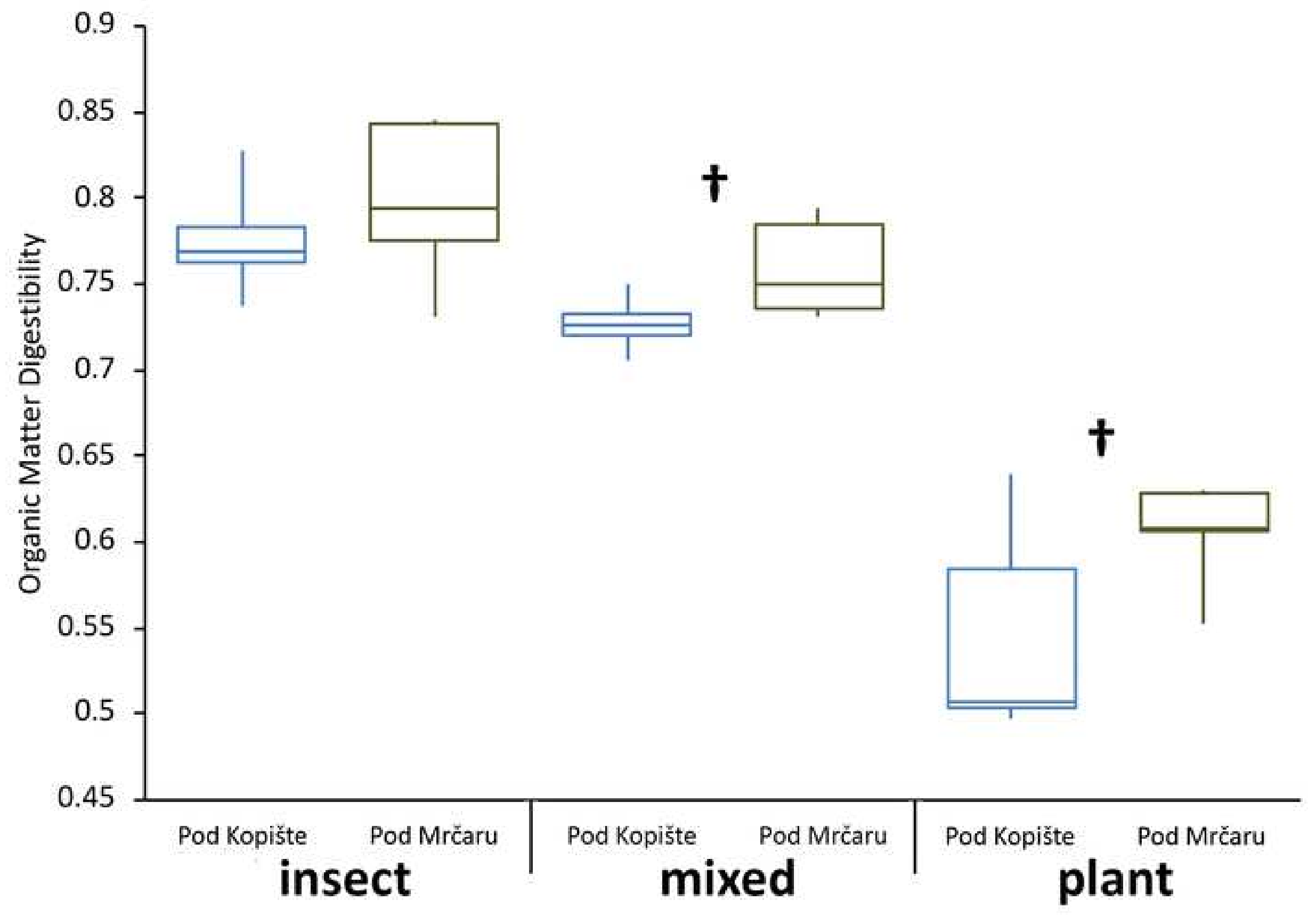




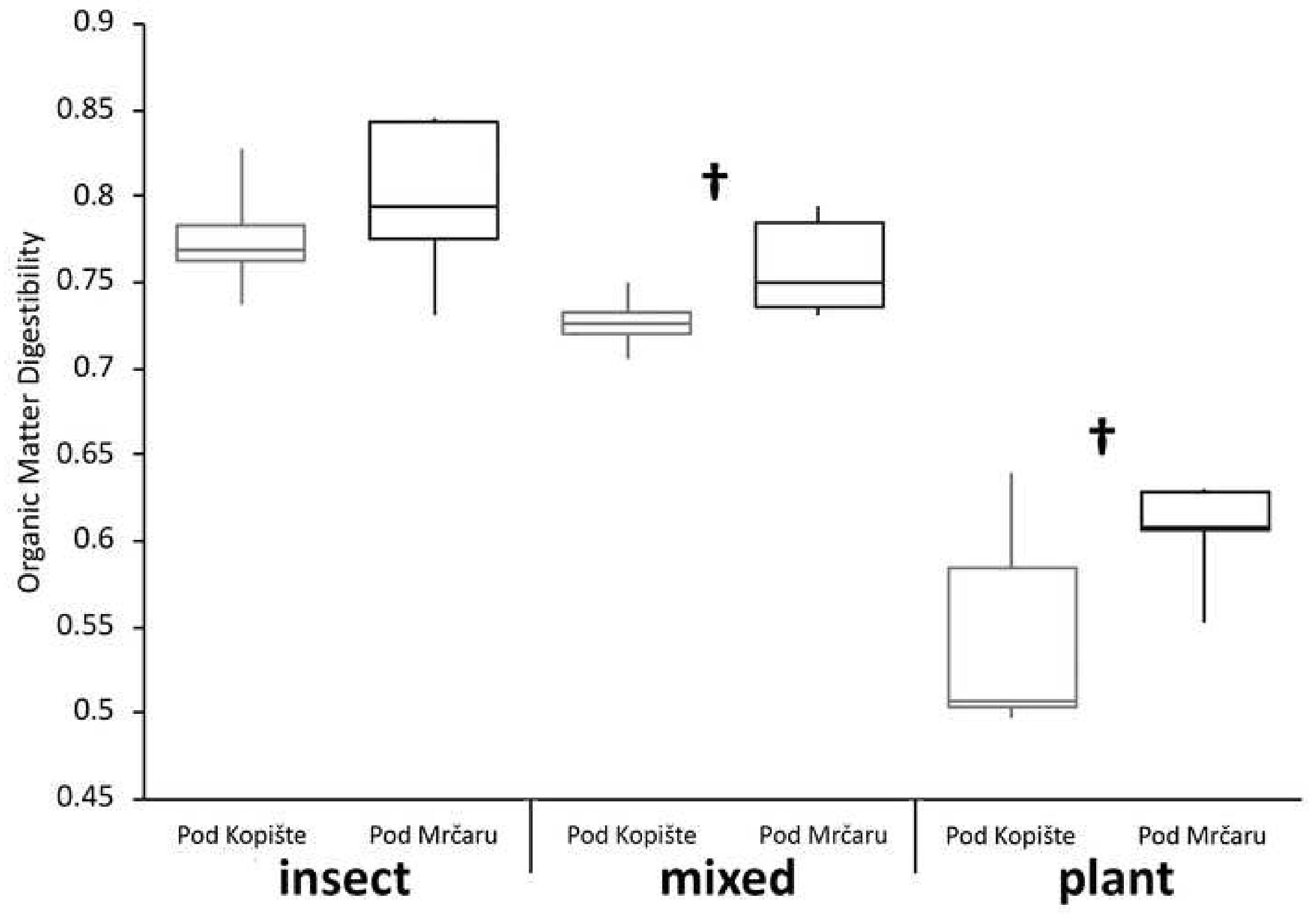


Wehrle et al. Supporting Information

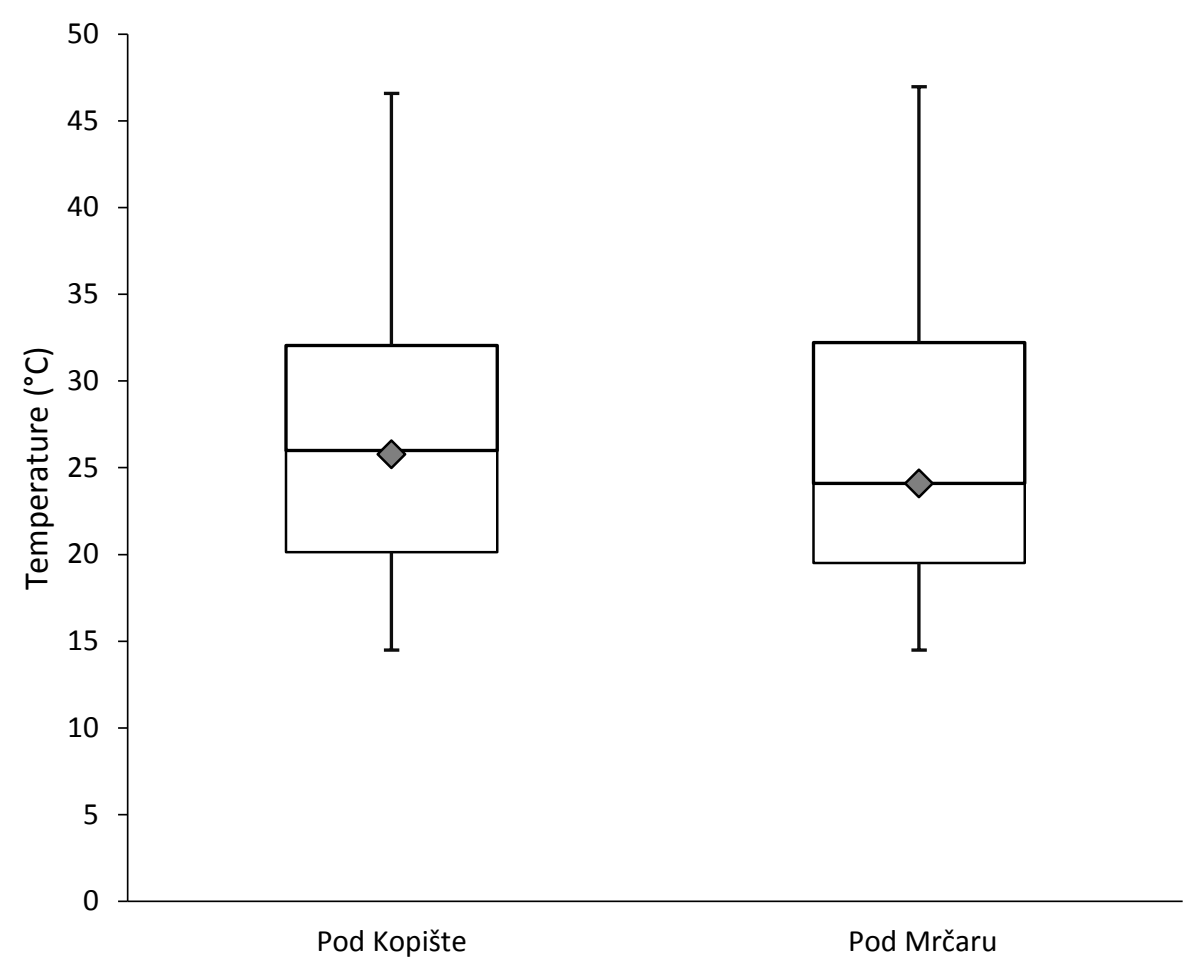

Figure S1. Box-plot of iButton temperature data collected on islands from May-September.

Temperatures were collected from three loggers/ island every 1.5-2 hours, with both full sun and shade represented. Quartile data are represented by boxes and whiskers, with means denoted by $\checkmark$. Temperatures are not different by island. 
Wehrle et al., Supporting information

Table S1. (a) Average SVL $( \pm$ SD) and (b) average body mass ( \pm SD) of lizards in digestibility trial from Pod Kopište and Pod Mrčaru. Initial measured from first measurement during the feeding trial, final from measurement at sacrifice. Percent change is calculated with respect to initial measurement. Pooled includes all lizards from a population regardless of diet treatment.

\begin{tabular}{|c|c|c|c|c|c|c|}
\hline $\mathbf{a}$ & $\begin{array}{l}\text { Pooled SVL } \\
\text { Initial }\end{array}$ & Final & $\%$ Change & $\begin{array}{l}\text { Change in } \\
\text { insectivore }\end{array}$ & $\begin{array}{l}\text { SVL by die } \\
\text { omnivore }\end{array}$ & $\begin{array}{l}\text { reatment } \\
\text { herbivore }\end{array}$ \\
\hline Pod Kopište & $61.32 \pm 2.8 \mathrm{~mm}$ & $62.72 \pm 3.3 \mathrm{~mm}$ & $2.31 \pm 3.8 \%$ & $5.07 \pm 4.5 \%$ & $1.22 \pm 3.7 \%$ & $0.65 \pm 1.6 \%$ \\
\hline Pod Mrčaru & $64.42 \pm 3.7 \mathrm{~mm}$ & $67.6 \pm 2.9 \mathrm{~mm}$ & $5.16 \pm 5.6 \%$ & $9.37 \pm 6.2 \%$ & $1.69 \pm 3.3 \%$ & $4.42 \pm 4.8 \%$ \\
\hline
\end{tabular}

\begin{tabular}{|c|c|c|c|c|c|c|}
\hline b & $\begin{array}{l}\text { Pooled mass } \\
\text { Initial }\end{array}$ & Final & $\%$ Change & $\begin{array}{l}\text { Change in } \\
\text { insectivore }\end{array}$ & $\begin{array}{l}\text { lass by di } \\
\text { omnivore }\end{array}$ & $\begin{array}{l}\text { treatment } \\
\text { herbivore }\end{array}$ \\
\hline Pod Kopište & $6.23 \pm 0.6 \mathrm{~g}$ & $6.19 \pm 0.6 q$ & $-0.45 \pm 6.5 \%$ & $-0.77 \pm 5.9 \%$ & $1.75 \pm 8.9 \%$ & $-2.34 \pm 5.0 \%$ \\
\hline Pod Mrčaru & $8.06 \pm 5.8 \mathrm{~g}$ & $8.04 \pm 0.5 \mathrm{~g}$ & $0.02 \pm 7.1 \%$ & $-2.65 \pm 5.1 \%$ & $5.01 \pm 5.4 \%$ & $-2.31 \pm 8.5 \%$ \\
\hline
\end{tabular}


Wehrle et al. Supporting Information

Table S2. Values (mean, with 95\% confidence interval below) for SVL, body mass, gut length, and gut mass Values that share a superscript letter for a particular measurement are not significantly different.

\begin{tabular}{cccc} 
SVL & $\begin{array}{c}\text { Pod Kopište } \\
64.39 \mathrm{~mm}^{\mathrm{A}} \\
(63.08-65.70)\end{array}$ & $\begin{array}{c}\text { Pod Mrčaru } \\
68.73 \mathrm{~mm}^{\mathrm{B}} \\
(67.36-70.11)\end{array}$ & $\begin{array}{c}\text { Zagreb } \\
68.43 \mathrm{~mm}^{\mathrm{B}} \\
(65.30-71.56)\end{array}$ \\
\hline Body mass & $\begin{array}{c}6.6 \mathrm{~g}^{\mathrm{A}} \\
(6.3-7.0)\end{array}$ & $\begin{array}{c}7.6 \mathrm{~g}^{\mathrm{AB}} \\
(7.3-7.9)\end{array}$ & $\begin{array}{c}8.6 \mathrm{~g}^{\mathrm{B}} \\
(8.3-8.8)\end{array}$ \\
\hline Gut length & $115.47 \mathrm{~mm}^{\mathrm{A}}$ & $116.15 \mathrm{~mm}^{\mathrm{A}}$ & $126.02 \mathrm{~mm}^{\mathrm{A}}$ \\
& $(108.29-122.66)$ & $(110.65-121.64)$ & $(117.93-134.11)$ \\
\hline Gut mass & $0.225 \mathrm{~g}^{\mathrm{A}}$ & $0.266 \mathrm{~g}^{\mathrm{A}}$ & $0.221 \mathrm{~g}^{\mathrm{A}}$ \\
& $(0.189-0.277)$ & $(0.233-0.312)$ & $(0.182-0.277)$
\end{tabular}


Wehrle et al. Supporting Information

Table S3. Average enzyme activities \pm standard deviation. ${ }^{a} \mathrm{~N}$-acetyl- $\beta$-D-glucosaminidase

\begin{tabular}{|c|c|c|c|c|}
\hline Enzyme, units & Region & Pod Kopište & Pod Mrčaru & Zagreb \\
\hline $\begin{array}{l}\text { Amylase, } \\
\mu m o l \text { glucose liberated } \min ^{-1} \mathrm{~g}^{-1}\end{array}$ & $\mathrm{HC}$ & $0.400 \pm 0.30$ & $2.387 \pm 1.99$ & undetectable \\
\hline $\begin{array}{l}\text { maltase, } \\
\mu \mathrm{mol} \text { glucose liberated } \mathrm{min}^{-1}\end{array}$ & total & $0.0435 \pm 0.027$ & $0.0694 \pm 0.023$ & $0.0701 \pm 0.029$ \\
\hline $\begin{array}{l}\text { trehalase, } \\
\mu \mathrm{mol} \text { glucose liberated } \mathrm{min}^{-1}\end{array}$ & total & $0.0548 \pm 0.041$ & $0.0900 \pm 0.075$ & $0.0569 \pm 0.020$ \\
\hline $\begin{array}{l}\beta \text {-glucosidase, } \\
\text { nmol MUB released } \text { min }^{-1} g^{-1}\end{array}$ & $\mathrm{PI}$ & $9.834 \pm 4.08$ & $7.362 \pm 1.50$ & $2.706 \pm 1.49$ \\
\hline $\begin{array}{l}\beta \text {-galactosidase, } \\
\text { nmol MUB released } \min ^{-1} \mathrm{~g}^{-1}\end{array}$ & $\mathrm{PI}$ & $22.461 \pm 8.51$ & $14.647 \pm 6.82$ & $17.332 \pm 8.57$ \\
\hline $\mathrm{NAG}^{\mathrm{a}}, \mathrm{nmol}$ MUB released $\mathrm{min}^{-1} \mathrm{~g}^{-1}$ & $\mathrm{PI}$ & $4.022 \pm 1.43$ & $1.845 \pm 0.70$ & $2.076 \pm 1.50$ \\
\hline $\begin{array}{l}\text { Trypsin, } \\
\text { nmol p-nitroaniline released } \min ^{-1} g^{-1}\end{array}$ & $\mathrm{HC}$ & $0.545 \pm 0.23$ & $3.150 \pm 2.01$ & $2.852 \pm 3.85$ \\
\hline $\begin{array}{l}\text { aminopeptidase, } \\
\mu m o l ~ p \text {-nitroaniline released } \min ^{-1}\end{array}$ & total & $0.196 \pm 0.05$ & $0.326 \pm 0.09$ & $0.485 \pm 0.09$ \\
\hline $\begin{array}{l}\text { Lipase, } \\
\text { nmol p-nitrophenol released } \text { min }^{-1}\end{array}$ & total & $0.411 \pm 0.09$ & $0.524 \pm 0.30$ & $0.599 \pm 0.29$ \\
\hline
\end{tabular}


Wehrle et al. Supporting Information

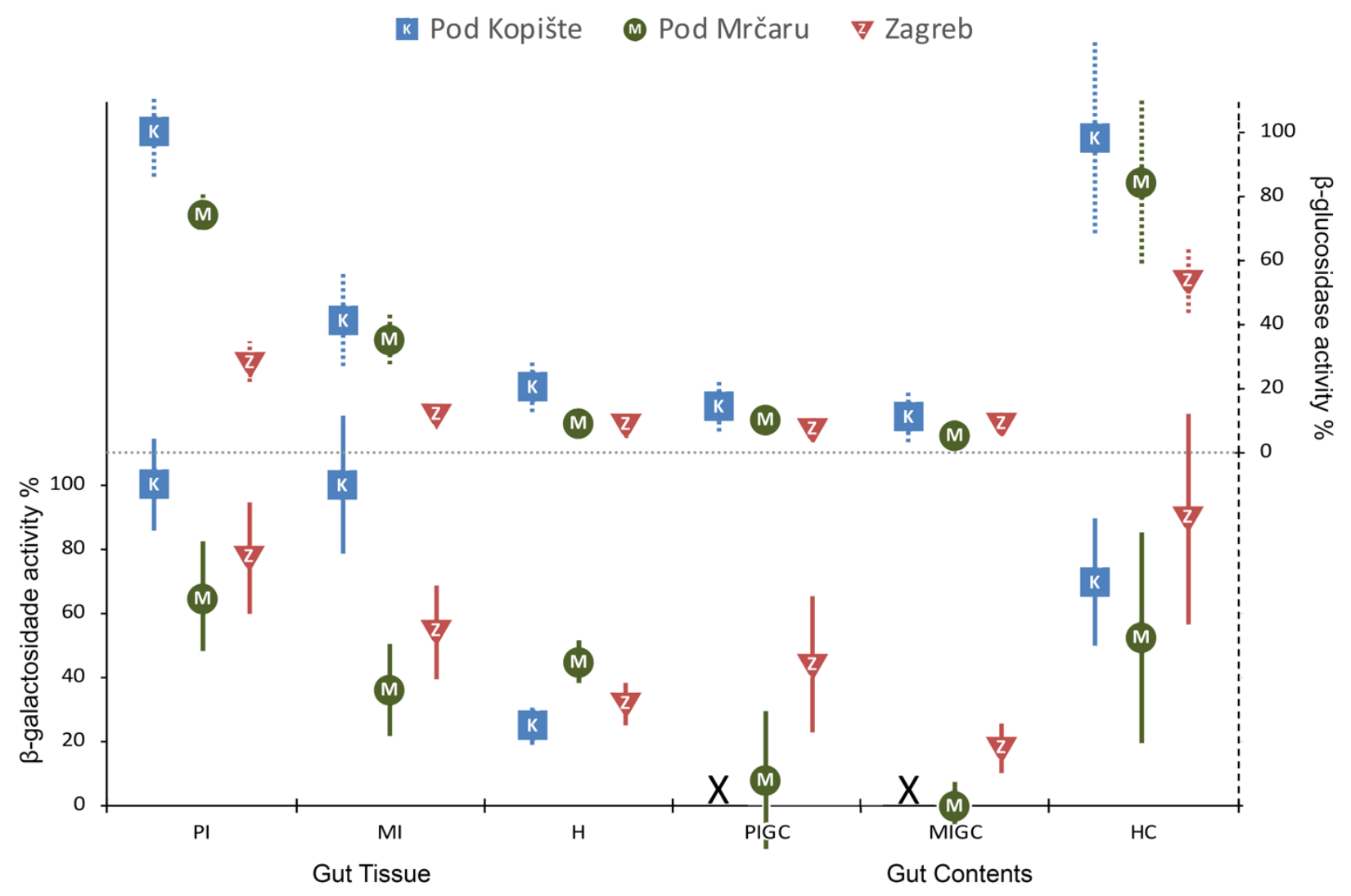

Figure S2. $\beta$-galactosidase (top graph, left axis, solid lines) and $\beta$-glucosidase (bottom graph, right axis, dashed lines) activities in each gut region as a percentage of the highest activity (i.e.: Pod Kopište PI activity is $100 \%$ for both enzymes as it has the highest activity of any gut region and lizard population). Values are averages \pm SEM. 


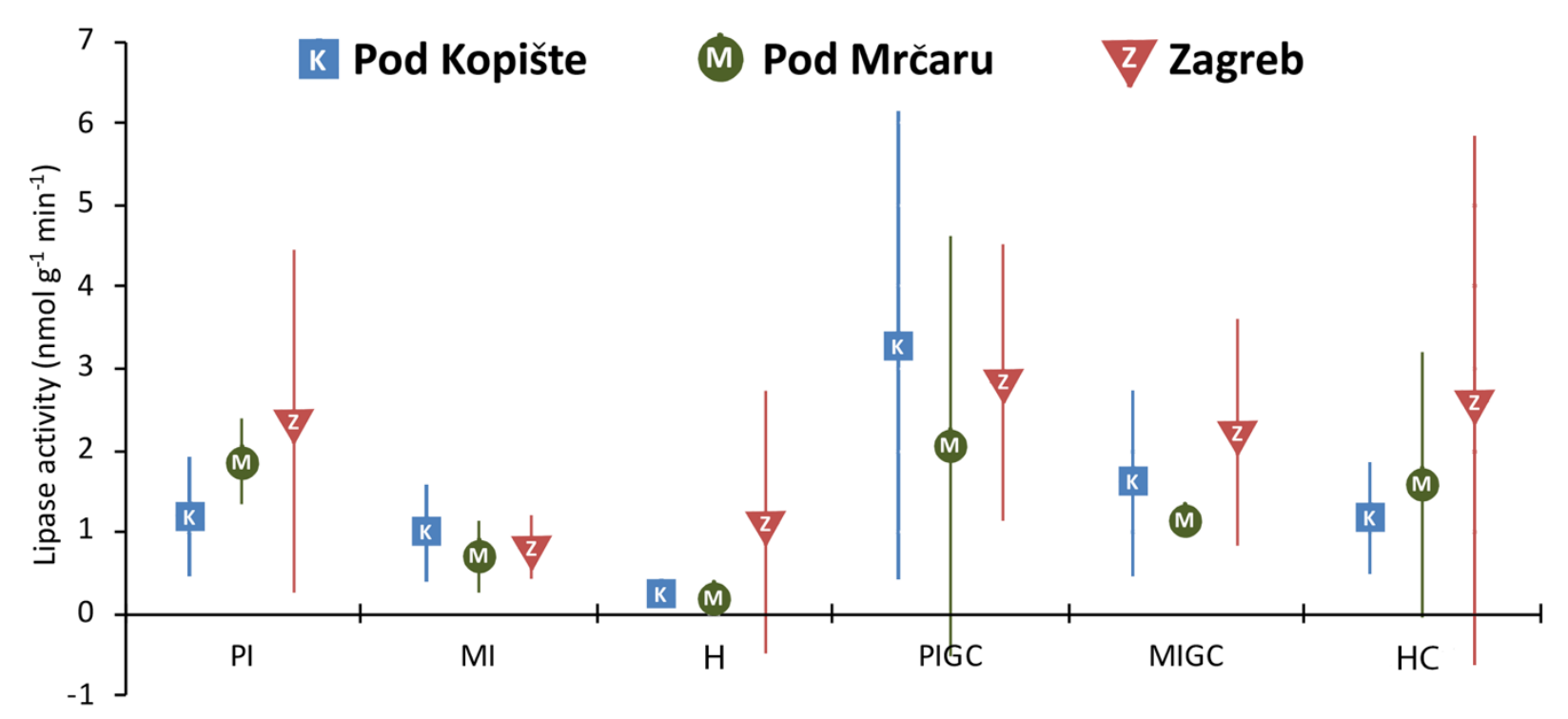

Figure S3. Lipase activity in nmol p-nitrophenol liberated $\mathrm{min}^{-1}$ for each gut region in Pod Kopište (source), Pod Mrčaru (new omnivore), and Zagreb (mainland) populations. Gut regions are proximal intestine $(\mathrm{PI})$, mid intestine $(\mathrm{MI})$, hindgut $(\mathrm{H})$, proximal intestinal gut contents (PIGC), mid intestinal gut contents (MIGC), and hindgut contents (HC). Values are mean \pm standard deviation. Pod Kopište $n=4-7$, Pod Mrčaru $n=4-6$ (MIGC region $n=2$ ), Zagreb $n=5-7$. There are no differences among populations by region. 
Wehrle et al. Supporting Information

Table S4. Average percent organic matter digestibility ( \pm standard deviation) on experimental diets of plant material, 50:50 plant material: insects, or insects in lizards from Pod Kopište and Pod Mrčaru $(n=5) . \dagger$ denotes significantly different at a $P=0.05$ level.

\begin{tabular}{c|ccc} 
& Pod Kopište & Pod Mrčaru \\
\hline plant & $54.6 \pm 6.3$ & $\dagger$ & $60.5 \pm 3.2$ \\
mixed & $72.0 \pm 1.6$ & $\dagger$ & $75.9 \pm 2.9$ \\
insect & $77.6 \pm 3.3$ & & $79.8 \pm 4.8$
\end{tabular}

Note: Plant diet comparison: ANCOVA: population $F_{1,6}=6.17, P=0.048$, body mass $F_{1,6}<0.001$, $P=0.983)$. Omnivore diet comparison: ANCOVA: population $F_{1,7}=5.875, P=0.0458$; body mass $F_{1,7}=3.065, P=0.1235$. 
Wehrle et al. Supporting Information

\section{Herbivore diet}

- $\quad$ ANOVA $F_{1,8}=3.48, P=0.099$

- ANCOVA: $S V L F_{1,7}=0.717, P=0.425$, population $F_{1,7}=3.357, P=0.110$

- ANCOVA: duration $\mathrm{F}_{1,7}=2.793, \mathrm{P}=0.1386$, population $\mathrm{F}_{1,7}=4.261, \mathrm{P}=0.0779$

- ANCOVA: intake $F_{1,6}=3.176, P=0.1250$, population $F_{1,6}=5.700, P=0.0542$, population*intake $F_{1,6}=3.926, P=0.0949$

\section{Omnivore diet}

- $\quad$ ANOVA $F_{1,8}=4.67, P=0.0627$

- ANCOVA: $S V L F_{1,7}=3.346, P=0.1101$, population $F_{1,7}=6.040, P=0.0436$

- ANCOVA: duration $\mathrm{F}_{1,7}=0.4342, \mathrm{P}=0.5292$, population $\mathrm{F}_{1,7}=4.342, \mathrm{P}=0.0757$

- ANCOVA: intake $F_{1,7}=1.271, P=0.297$, population $F_{1,7}=4.829, P=0.064$

\section{Insectivore diet}

- $\quad$ ANOVA $F_{1,8}=0.703, P=0.426$

- ANCOVA: $S V L F_{1,7}=2.22, P=0.180$, population $F_{1,7}=0.811, P=0.398$

- ANCOVA: duration $\mathrm{F}_{1,7}=1.37, \mathrm{P}=0.281$, population $\mathrm{F}_{1,7}=0.735, \mathrm{P}=0.281$

- ANCOVA: intake $\mathrm{F}_{1,7}=2.57, \mathrm{P}=0.153$, population $\mathrm{F}_{1,7}=0.841, \mathrm{P}=0.390$ 
Wehrle et al. Supporting information

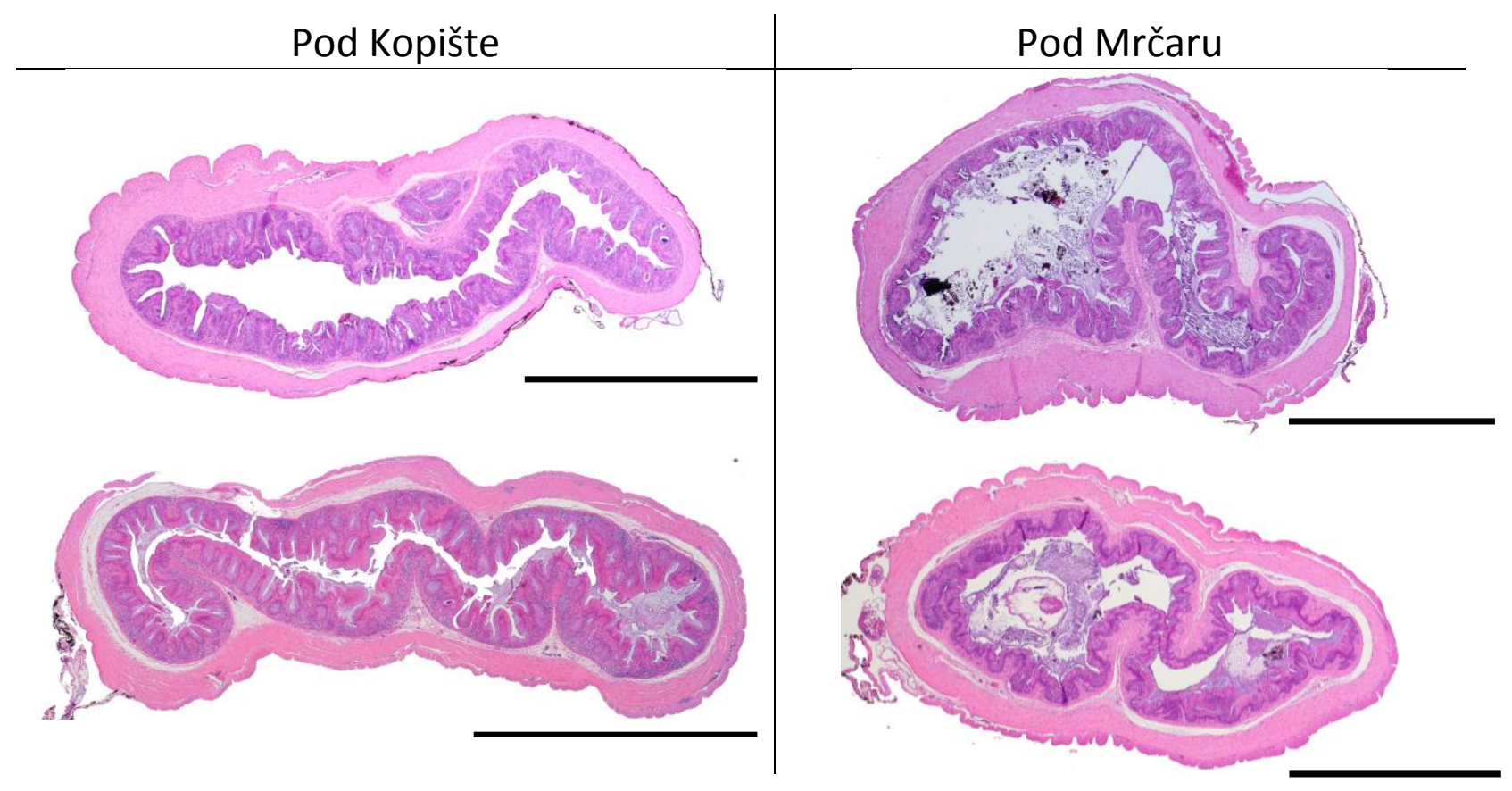

Figure S4. Cross section images are representative stained histological sections from the hindgut of Pod Kopište (source) and Pod Mrčaru (new omnivore) populations (not to scale). Each section from a different individual collected in spring 2014 (Wehrle 2018). Scale bars to the lower right of each image are $100 \mu \mathrm{m}$ for that image. 


\section{GENERAL COMMENTS}

We are supportive of this paper overall, yet we request that you be more upfront regarding the limitations or caveats of the study. I suggest adding these in a final paragraph titled something like "Limitations of the Present Study and Future Directions."

We changed the final section of the manuscript to "Conclusions, Potential Limitations, and Future Directions", and we added in the information below.

Into a Future Directions could also go mention of things like "We are analyzing gastric enzymes (including pepsin and chitinase) for a different study and did not include them here."

We added the following sentence to the final section of the manuscript: "Moreover, as the stomach can play a major role in the digestive process, and can account for greater than $50 \%$ of gut transit time (Karasov and Martínez del Río 2007), more work on gastric function is warranted, and is the subject of our own work on this system."

\footnotetext{
1. Unless I totally missed something, this is not a common-garden experiment, so we cannot know that the differences are evolved, genetically based. Please say this more clearly and cite this paper:

Garland, Jr., T., and S. C. Adolph. 1991. Physiological differentiation of vertebrate populations. Annual Review of Ecology and Systematics 22:193-228.
}

We added the following sentences to the final section of the discussion: "Although we know the Pod Mrčaru lizards have changed their body morphology over ecological time (Herrel et al. 2008), any shifts in their digestive physiology appears to be more constrained on this timescale, or mitigated by differences in behavior and ecology. We currently do not know whether these changes represent flexibility (Piersma and Drent 2003), or evolved differences with underlying genetic changes (Garland and Adolph 1991). Some dietary shifts may not be as limited by physiology as they are by these animals' ecology."

I don't see a claim that the population differences reflect evolved differences, but that is the impression one gets in reading over the paper. We need to make sure that readers don't think you have demonstrated something that you have not demonstrated. You do use "rapid evolution" as a keyword (which is a little sneaky, but probably OK to help attract readers). Please consider changing wording that leaves readers with an incorrect impression of your findings.

We removed "rapid evolution" from the key words because we agree that we don't want to give this impression. We have been careful to say that we don't know whether any differences (which we argue are subtle) are evolved or flexibility. We do note the different digestibilities measured in the laboratory, but don't argue that this is an evolved ability.

2. The study is very close to a 2-species comparison, so please explain for the reader why the problems indicated in this paper below are not of major concern in the present study:

Garland, Jr., T., and S. C. Adolph. 1994. Why not to do two-species comparative studies: limitations on inferring adaptation. Physiological Zoology 67:797-828. Please keep in mind that PBZ's readers include younger scholars seeking direction from published studies.

The final paragraph of the manuscript now reads: "We do recognize that this study can be mistaken as a "two species comparison", which comes with caveats and cautions (Garland and Adolph 1994), especially when comparing the island populations with the mainland 
population in Zagreb. However, most of our work is focused on comparing the two island populations, which according to their 16s rRNA sequences, have not diverged much genetically over 30+ years of separation (Herrel et al. 2008). The similarity among the two island populations may, thus, simply represent that they are still very much the same taxon phylogenetically, and thus, may not be treated as separate entities. The similarity of the Pod Mrčaru and Pod Kopište lizards in comparison to the Zagreb population, should, therefore, not be surprising given the short period of time of the island populations' separation (Nevo 1971; Herrel et al. 2008). Similar results among populations of insular vs mainland populations of lizards have been observed in other species (Pafilis et al. 2007; Sagonas et al. 2015)."

I do see the paragraph on lines 601-605, but this is somewhat facile. Also, what data are being referred to in the phrase "in the laboratory?" Is that from the present study or something else?

We did include in this study an experiment in the laboratory in which we fed male lizards from the two island populations carnivore, omnivore, and herbivore diets. We collected feces and measured digestibility.

\section{FIGURES}

Regarding the color figures: We will provide free color figures in print for the histology photos. For the graphs, please provide grayscale images. If you would like the graphs to be color online: when you submit your revised paper, retain the color images in your manuscript as well as uploading the grayscale versions. We will ask our publisher to use the grayscale versions for the print edition and the color versions for the electronic edition.

We have provided color and gray scale versions of the figures, but kept the histological images in Fig. 4 in color (while making the rest of the figure grayscale).

You might consider changing the line style of Figure S2 to match anything similar in the main text.

This graph has been modified to look like the other enzyme figures.

\section{SPECIFIC COMMENTS}

Line 29: Is this supposed to say "The Pod Mrčaru populationS?"

No. It is one population on Pod Mrčaru.

Line 33-34: "than the plant-eating Pod Mrčaru population" This sounds like the two populations on Pod Mrčaru differ in diet, but that difference was not made clear earlier in the Abstract. I may be confused by the sampling scheme, which is clear in Table 1 but confusing here in the Abstract. 
We understand. We changed this to read "omnivorous" since that is how we described the Pod Mrčaru lizards earlier in the abstract.

Line 38: Say how long they had been acclimated "in the laboratory" and indicate if this was just adults or over ontogeny.

We reworded this sentence as follows: "Although subtle, the changes in hindgut digestive physiology impact digestibility of plant material in adult lizards - Pod Mrčaru lizards had higher digestibility of herbivorous and omnivorous diets fed over several weeks in the laboratory than did their source population."

\footnotetext{
Lines 45-51: The idea that organs are expensive and so likely to be downregulated via phenotypic plasticity is not new and indeed is discussed in MANY areas of physiology/morphology. This argument is, of course, similar to the evolutionary arguments about use and disuse, e.g., regarding blind cave fish, the human appendix, etc., etc., etc. These arguments probably go back to Aristotle and are received wisdom in both physiology and evolutionary biology. They are common sense. A couple of sentences should be added to the start to say this. Then transition into the gut via "For example, ..." You might also add that the gut is known to change rapidly as compared with some other organs and organ systems, and give some comparative data showing this.

I cannot find Krasov (1992) in the literature cited, so I could not check it, but is this really the first place someone made such arguments for the digestive system? Hard to believe. Anyway, how is the AMH anything more than common sense?
}

Line 46: AMH. Was this stated with respect to phenotypic plasticity, evolutionary adaptation, or both?

The AMH deals with both, short-term flexibility, and long-term adaptive patterns. The history of this hypothesis is more than "just so" stories, emerging from the laboratory of Jared Diamond in the 80's and 90's. The reason we cite it here is because it is specific to the gut, and to the function of digestive enzymes and nutrient transporters in particular. A direct quote from Karasov and Diamond (1983): "Dietary substances that yield calories but are not nutritionally essential will specifically stimulate their own absorption. The prime example is likely to be the effect of dietary carbohydrate on glucose transport. The mechanism will be substrate-dependent induction of carriers, expressed kinetically in increased maximal transport rate $\left(V_{\max }\right)$." This paper from 1983 led to the formal coining of the AMH and the highly-cited review (Karasov 1992). The AMH has spurred dozens of studies in nutrient transporters and digestive enzymes, and whether their rates of activity are stimulated by their substrates. The AMH is well-supported for carbohydrates in particular, from the physiological (i.e., digestibility) to the genetic level (discussed in Heras et al. 2020). So, although there are other "non-use" arguments for why certain traits may change, the AMH is more functional because it uses Chemical Reactor Theory (CRT) to make some first order approximations and predictions about specific aspects of gut function. For our intent here, these are the best citations to use as a starting point for the specific predictions we make about enzyme activities in the Croatian lizards. We have adjusted the opening paragraph so that it is clear that this can be viewed on short or long time scales, and provide examples of both (long time scales for carbohydrates, more short time scale for proteins). The fact that we largely reject the AMH in the island populations is of interest to a general audience, and thus, we focus on this fact to open the discussion.

Although we have included the CRT proportions (that are currently in the supplements) in earlier versions of this manuscript, we are hesitant to bring them in here because Bill Karasov (previous reviewer of this manuscript) and Steve Secor (current 
editor of this manuscript) didn't like our use of the CRT proportions in this context. So, our compromise in earlier versions was to move the CRT discussion into the supplements. Thus, from our perspective, being asked to reintegrate the CRT proportions in the introduction goes against the recommendations of two prominent digestive physiologists, and the author of the AMH itself. Karasov and Secor were fine with us using the AMH to make predictions, but leaning on the CRT proportions seemed to make them uncomfortable. Hence, we are hesitant to reintegrate the CRT proportions into the introduction at this stage. We would prefer to just eliminate the supplemental introduction section altogether and refer readers to the citations.

We added Karasov (1992) as well as Karasov and Diamond (1983) to the literature cited.

I agree with Reviewer 1 that the introductory material currently in Supporting Information makes little sense there and instead needs to go into the Introduction.

Please see our response above. We prefer to eliminate the supplemental introduction altogether and lean more on citations provided in the introduction to refer readers to the theoretical underpinnings of the AMH itself.

Reviewer 3 previously commented about particle size. What you say in response is fine, but please add some of that into the manuscript, either in Methods or maybe in the Final Caveats section.

We added the following to lines 309-317 in the methods, "We recognize that grinding the food to small particle sizes may take away natural particle size differences in the diets of the Pod Kopište and Pod Mrčaru lizards. However, in seeking some control over dietary intake, we chose to grind the food into a common size, and thus, measure digestibility based on more uniform food. This removed potential physical and chemical processing of differentially sized food particles in the lizards, but allowed us to focus on pure chemical digestibility in the laboratory. One previous investigation of whole meal worm digestibility in these same lizard populations found similar results to ours (Vervust et al. 2010), suggesting that our grinding of the food didn't mask any performance differences among the lizard populations."

Lines 94 -95 and elsewhere. Change "While" to "Whereas" or "Although." "While" means literally later in time.

These have all been changed or removed.

Line 103: Change punctuation to be "; however,"

Change made.

Line 639-640: Change to "may dampen selection on ..." Selection does not have units of pressure.

Pressures removed. 


\section{Change made.}

Line 963-964: Decapitalize title and check other references.

\section{Decapitalized and references checked.}

Table 2: Unclear if these empty stomach individuals are an additional number of animals versus the sample sizes listed inside the table. Clarify so that someone could calculate \% empty.

To the Table 2 caption, we added that the empty stomachs were not included in the counts, but we provided the number of empty stomachs. Thus, if someone wants to redo the calculations with the empty stomachs, they have that information now.

FYI, this is relevant:

Supporting Materials for the Introduction. As noted above, please move all of this into the text and make it flow. In the middle of the third paragraph here, add something like "either in terms of phenotypic plasticity (ontogenetic acclimatization) and/or evolved differences" to help make it clear that both things may be going on. This will also foreshadow the Caveats section where you make clear that you don't know which of these explains the population differences you have found.

\section{We believe we have clarified this throughout the manuscript. Please see our response about the supplemental material above.}

Reviewer 1 Comments

I have carefully read through the manuscript and the response to reviewers, and the authors have done an excellent job in revising the manuscript and responding to my comments and criticisms. I look forward to seeing this work in its final and published form.

\section{Thank you.}

